EPJ Web of Conferences 18, 05001 (2011)

DOI: $10.1051 /$ epjconf/20111805001

(C) Owned by the authors, published by EDP Sciences, 2011

\title{
Meteorites and cosmic dust: Interstellar heritage and nebular processes in the early solar system
}

\author{
C. Engrand ${ }^{\mathrm{a}}$ \\ CSNSM CNRSIIN2P3-Univ. Paris Sud, Bâtiment 104, 91405 Orsay Campus, France
}

\begin{abstract}
Small solar system bodies like asteroids and comets have escaped planetary accretion. They are the oldest and best preserved witnesses of the formation of the solar system. Samples of these celestial bodies fall on Earth as meteorites and interplanetary dust. The STARDUST mission also recently returned to Earth cometary dust from comet 81P/Wild 2, a Jupiter Family Comet (JFC). These samples provide unique insights on the physico-chemical conditions and early processes of the solar system. They also contain some minute amount of materials inherited from the local interstellar medium that have survived the accretion processes in the solar system.
\end{abstract}

\section{INTRODUCTION}

The study of extraterrestrial samples has allowed to open a window in the composition, physicochemical and dynamical processes of the formation of the solar system. In particular, the study of extraterrestrial samples can give informations on the nature and composition of materials that were inherited from the local interstellar medium, and on processes that were at work in the early solar system to transform this matter into solar material. In this chapter, we will give a brief presentation of primitive samples that retained the memory of the formation of the solar system (section 2), to get insights on: (i) the nature and composition of material inherited from the local interstellar medium that survived the accretion processes in the solar nebula (section 3); (ii) the early solar system chronology (section 4); (iii) the structure and composition of the protoplanetary disk (section 5).

\section{PRIMITIVE SAMPLES: SMALL BODIES OF THE SOLAR SYSTEM}

The memory of the formation of the solar system has only been preserved in primitive samples, i.e. bodies that have not (or little) been altered since their formation. Asteroids and comets are small enough to have escaped geological processes that transformed primitive planetesimals into planets, although some of them could have suffered various degrees of aqueous and thermal alteration.

Meteorites collected on Earth provide samples from asteroids, whereas samples from comets are more difficult to recover. Stored at low temperature at heliocentric distances greater than 50 astronomical units (AU), comets were thought to contain a larger amount of well preserved interstellar matter than asteroids, but recent results challenge that assumption (e.g. [1]). Although some meteorites have been proposed to have a cometary origin, the only certified cometary samples available on Earth were brought back in January 2006 by the NASA STARDUST mission, returning dust from the Jupiter Family Comet (JFC) 81P/Wild2. Cosmic dust in interplanetary space is known to have a dual origin, from asteroids and comets [e.g. 2], but until recently the identification of cometary dust particles were only tentative.

ae-mail: Cecile.Engrand@csnsm.in2p3.fr

This is an Open Access article distributed under the terms of the Creative Commons Attribution-Noncommercial License 3.0, which permits unrestricted use, distribution, and reproduction in any noncommercial medium, provided the original work is properly cited. 


\section{EPJ Web of Conferences}

The discovery of a new family of cometary dust particles in the Antarctic micrometeorite collection has allowed making connections with STARDUST samples [3, 4].

\subsection{Asteroids}

\subsubsection{Meteorites as asteroid samples}

Asteroids are small solar system bodies that escaped planetary accretion. They are stored in the asteroid belt located from 2 to 4 astronomical units between Mars and Jupiter. Meteorites are extraterrestrial rocks originating mostly from asteroids (a small number of them were also ejected from the Moon and Mars). Asteroidal meteorites are complex assemblages of anhydrous and hydrous minerals sometimes mixed with a small amount of organic compounds (the maximum $\mathrm{C}$ content is $\sim 5 \mathrm{wt} \%$ [5]). The meteoritic organic component is discussed by L. Remusat in this volume.

Meteorites are usually collected on the Earth's surface in hot and cold deserts (recovered stones are termed "finds"), or are occasionally looked for after the observation of their entry in the Earth's atmosphere ("falls").

Although not comparable to processes that led to planetary formation, some kind of alteration (thermal metamorphism or aqueous alteration) have affected most meteorites on their parent body. Meteorites are classified into groups that seem to have undergone the same kind of history since their formation. This does not necessarily mean that meteorites from a single class originate from the same parent body. There are currently about 40,000 meteorites classified in the collections worldwide. Meteorites are composed of two main types: chondrites and nonchondrites, with each of them having three to five classes comporting each two to a dozen of groups, etc... (see Table 1).

Nonchondrites are meteorites originating from differentiated parent bodies, and their studies are more relevant to planetary formation processes. Chondrites are non differentiated meteorites, with more than $80 \%$ of these meteorites being ordinary chondrites (OCs), whereas the most primitive meteorites, the carbonaceous chondrites (CCs), represent less than 5\% of the meteorites. Carbonaceous chondrites have suffered some aqueous alteration episodes, but their composition best matches that of the solar

Table 1. Classification of meteorites [from 6].

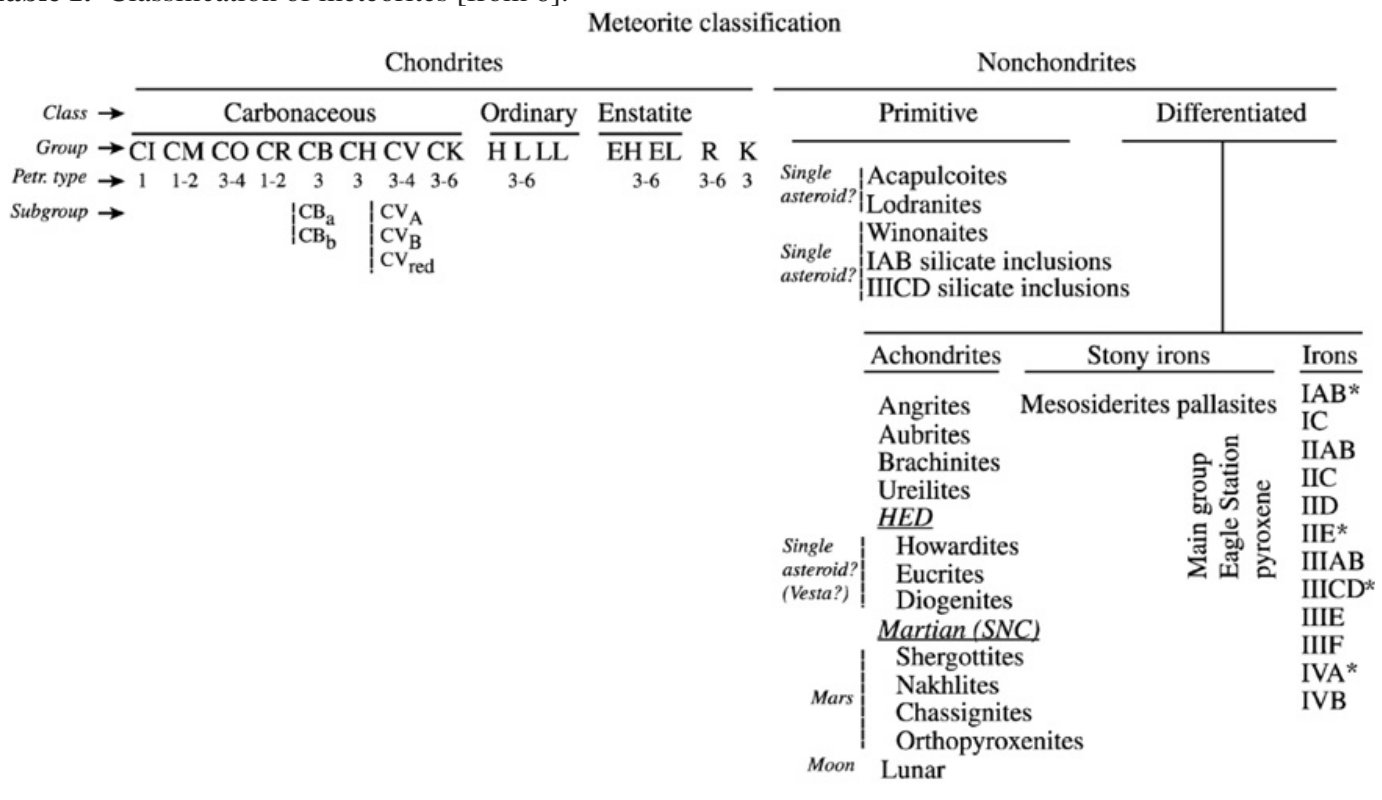

*irons with silicates 
photosphere, hence showing that they preserved the composition of the protosolar gas from which they formed, for non volatile elements [7].

Refractory inclusions. Mineral assemblages up to a few centimetres in size made of refractory components were first discovered as new objects in 1968 by M. Christophe Michel-Levy [8]. These refractory inclusions are made of minerals that formed at very high temperatures, above 1500-1600 K. Refractory inclusions are mostly found in carbonaceous chondrites (especially CV chondrites like the Allende meteorite), and rarely in ordinary and enstatite chondrites. Two kinds of refractory inclusions are found: inclusions dominated by $\mathrm{Ca}-\mathrm{Al}$-rich oxides and silicates (CAIs, Figure 1), and Amoeboidal Olivine Aggregates (AOAs) [9].

Since their discovery, CAIs have been investigated by numerous teams, and they turned out to be the oldest objects identified in the Solar System: their ages determined by radioactive clocks (between 4.567 and $4.568 \mathrm{Ga}$, see section 4) are taken as the age of the solar system. The minerals that constitute the CAIs were the first solid phases formed at high temperatures $(\mathrm{T}>1200 \mathrm{~K})$ in the protosolar disk.
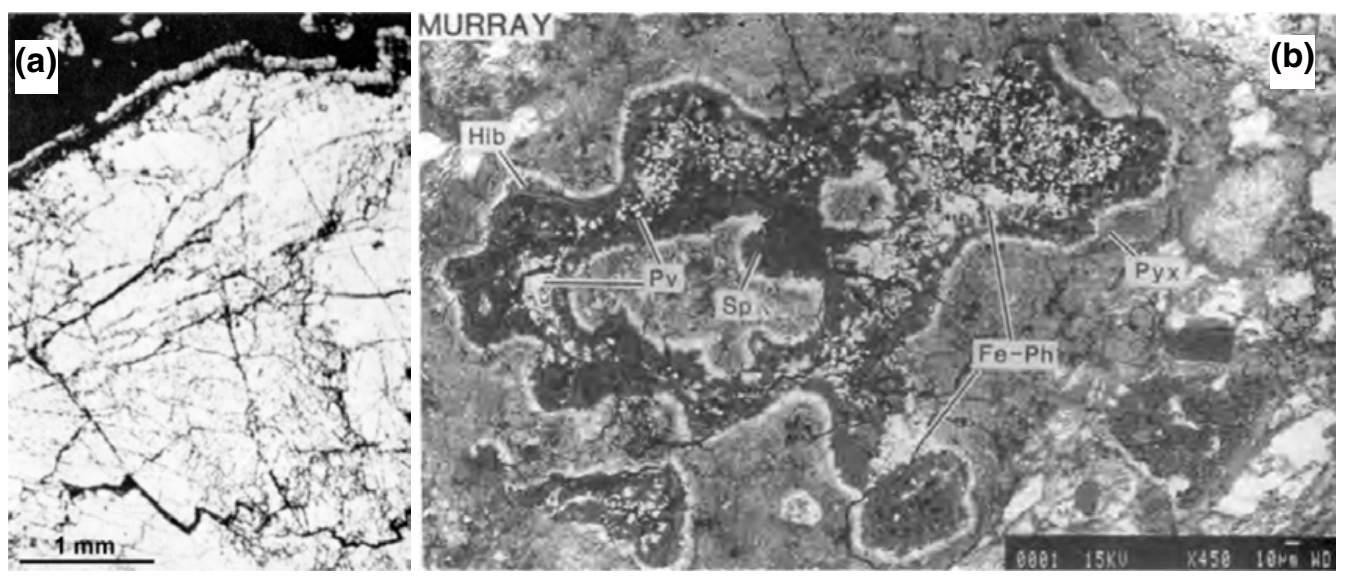

Figure 1. (a) Optical image of the first refractory inclusion (melilite-spinel) described by M. Christophe MichelLevy in 1968 (from [8]); (b) Backscattered electron micrograph of a spinel (Sp) - hibonite (Hib) - perovskite (Pv) refractory inclusion from the Murray carbonaceous chondrite $(\mathrm{CM})$. Iron-rich phyllosilicates $(\mathrm{Fe}-\mathrm{Ph})$ and pyroxene (Pyx) rim the inclusion (from [10]).

Chondrules. Chondrules are silicate droplets that have been frozen in a spherical shape, and that constitute the main mass of the chondrites. Chondrules are usually composed of ferromagnesian silicates (olivines and pyroxenes) enclosed in a glassy phase, the mesostasis, which has a composition enriched in $\mathrm{Al}$ and $\mathrm{Ca}$ compared to olivines and pyroxenes. Two major groups of chondrules are defined, based on their chemical composition: (i) Type I chondrules formed in reduced conditions, reflected by low $\mathrm{Fe}$ contents of the silicates constituting the chondrules, and the presence of $\mathrm{Fe}$ as metal inclusions or sulphides; (ii) Type II chondrules contain olivines and pyroxenes with more Fe in their structure, as FeO. The most abundant are Type I porphyritic chondrules (i.e. with a recrystallisation texture and possible relict minerals).

Matrix. The meteoritic refractory inclusions and chondrules described above are embedded in a finegrained matrix that contains both anhydrous and hydrated mineral phases at the $10 \mathrm{~nm}$ to $5 \mu \mathrm{m}$ size scale [e.g. 9]. In carbonaceous chondrites, these mineral components are also intimately mixed with organic matter that amounts to a few wt $\%$ of the meteorite. Phyllosilicates and carbonates potentially present in 
the matrix are usually interpreted as secondary phases (alteration products) resulting from the circulation of aqueous fluids on the parent body [11].

\subsubsection{The Hayabusa Mission: Sample return from asteroid Itokawa}

In May 2003, the Japanese spatial agency launched the Hayabusa interplanetary mission that arrived in September 2005 at Asteroid Itokawa (540 metre-long) (Figure 2), about 300 million kilometres from the Earth [e.g. 12-14, and companion papers].

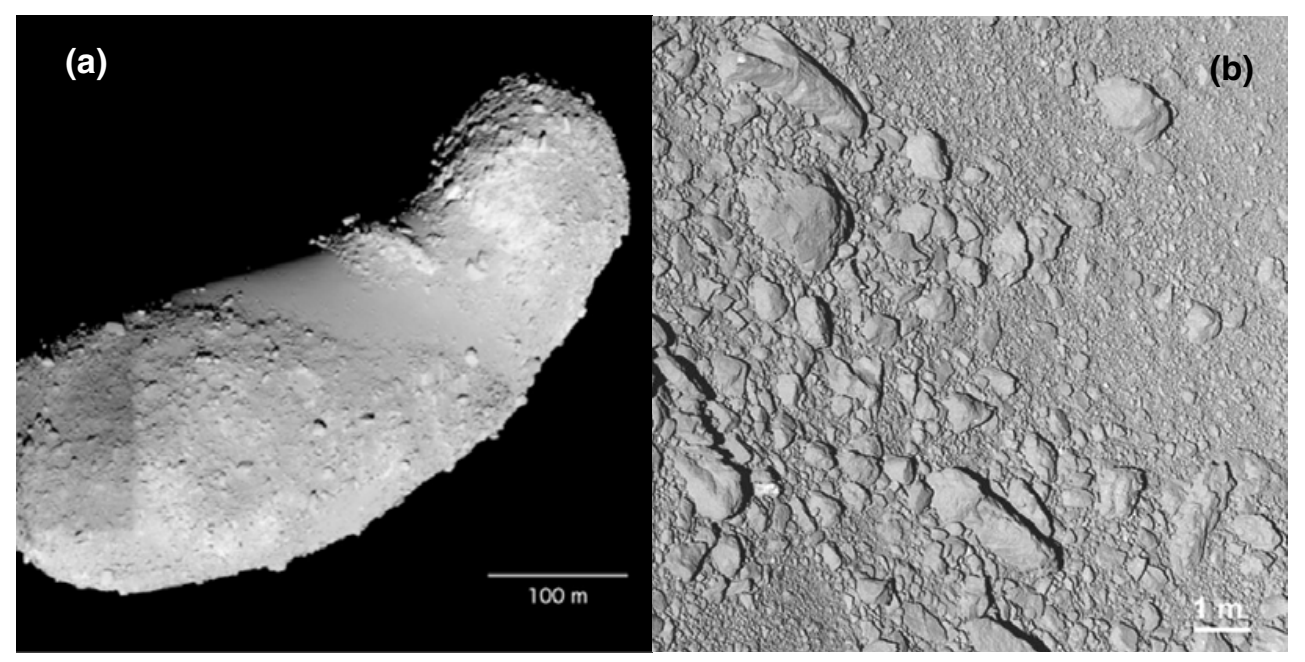

Figure 2. General (a), and detailed (b) view of asteroid Itokawa from the Japanese ISAS-JAXA Hayabusa spacecraft during encounter and landing in September- November 2005. A few thousands of grains $(<10 \mu \mathrm{m})$ from this asteroid were brought back to Earth in June 2010.

Hayabusa is the first asteroid sample return mission, and although some misfortunes happened to the spacecraft, the sample container was returned to Earth in June 2010. The very small grains (most of them $<10 \mu \mathrm{m}$ ) found in the container have recently been shown to be of extraterrestrial origin and are currently under investigation (http://www.jaxa.jp/press/2010/11/20101116_hayabusa_e.html). These tiny grains (about 1500) represent the first samples from a known asteroid returned to Earth and available for laboratory studies [15]. Recent results presented at the Lunar and Planetary Science Conference in March 2011 confirm the link between S-type asteroids and ordinary chondrites ([e.g. $16,17])$.

\subsection{Comets}

Comets are icy bodies from the outer regions of the solar system, stored at low temperatures $(\sim 10 \mathrm{~K})$ in two main reservoirs: the Edgeworth-Kuiper belt located beyond the orbit Neptune at $\sim 50 \mathrm{AU}$, and the Oort cloud which is a huge cometary reservoir extending at distances beyond 50,000 UA (i.e. $\sim 1$ light year, about a quarter of the way to the nearest star, Proxima Centauri). As comet reservoirs lie far from the Sun (and from the Earth), comets can only be characterized when their highly elliptical orbits bring them in the inner Solar System.

The possibility for some meteorites to have a cometary origin is debated. Until recently, in situ and remote sensing observations were the only source of knowledge on the structure and composition of comets. The NASA STARDUST sample return mission in 2006 represents an outstanding milestone in our understanding of cometary matter. However, the conclusions drawn from these samples have 
to be taken with some caution, as the samples were altered during their capture in the aerogel, and because they are representative of only one given comet. A complementary and promising path for a better understanding of cometary matter lies in the identification of cometary samples in the collection of extraterrestrial materials on Earth, especially in the cosmic dust collections.

\subsubsection{Are there cometary meteorites?}

Most meteorites originate in the asteroid belt, however some authors proposed that some meteorites (or meteorite types) could come from comets [e.g. 18-22]. This is in particular the case of the water- and organic-rich meteorite Orgueil [23]. This preeminent meteorite is the meteoriticists' reference, as its composition matches that of the solar photosphere, for non volatile elements [7, 24]. Results from the STARDUST spatial mission do not preclude the possible cometary origin of some primitive meteorites, however they cannot be recognized as such with certainty.

\subsubsection{In situ analysis and remote sensing of comets}

The GIOTTO and VEGA spatial missions have investigated the comet 1P/Halley in 1985-86 (e.g. [25-27]). Comets are also characterized by spectroscopic measurements that give informations on the volatile content and on the composition of the dust grains (e.g. [28, 29]) (see section 5).

\subsubsection{The STARDUST Mission: Sample return from Comet 81P/Wild 2}

The NASA STARDUST was launched in February 7, 1999 and successfully encountered comet Wild 2 on January 2, 2004. Wild 2 dust particles were brought back to Earth in January 2006 for laboratory studies and are preserved at the Johnson Space Center in Houston (see http://curator. jsc.nasa.gov/stardust/index.cfm).

STARDUST also collected interstellar dust, but the grains are small $(<1 \mu \mathrm{m})$ and the impact tracks are difficult to discriminate from defects in the aerogel [30, 31]. A web-based survey of the aerogel collectors was a success (http://stardustathome.ssl.berkeley.edu/), and four candidates of contemporary interstellar grain have been removed and are currently under investigation [32] (http://stardustathome.ssl.berkeley.edu/blog/).

\subsection{The special case of cosmic dust: Asteroidal and cometary origins}

Dust is present in interplanetary space and originates both from asteroids and comets, although the proportions of dust from each origin are still debated [e.g. 33-35]. Asteroidal dust is produced by collisions between asteroids, and cometary dust is released by sublimation of the cometary ice when comets approach the Sun.

Considering periods of time shorter than a million years, the mass flux of cosmic dust arriving on Earth is dominated by particles around $200 \mu \mathrm{m}$, and accounts for 30,000 $\pm 20,000$ tons/year (updated from [36]), that means $\sim 1000$ times more important than the meteorite flux [37]. Cosmic dust particles enter the terrestrial atmosphere with velocities varying between $\sim 11 \mathrm{~km} / \mathrm{s}$ (Earth's escape velocity) up to $\sim 70 \mathrm{~km} / \mathrm{s}$ or more for very elliptical orbits. Frictional heating with the atmosphere's layers causes a flash heating of the particles at high altitude $(\sim 80-120 \mathrm{~km})$. A large proportion of dust grains partially or totally melt (or evaporate) under this stress. However, a small fraction of unmelted cosmic dust particles remains in the incoming flux, and can be collected on Earth. Unmelted cosmic dust is mainly recovered from the terrestrial stratosphere and the polar caps. Historically, particles recovered from the stratosphere are called "IDPs" (for Interplanetary Dust Particles), whereas particles collected in the polar caps are named "micrometeorites". Due to their mode and location of collection, IDPs are small, from a few $\mu \mathrm{m}$ to $\sim 30 \mu \mathrm{m}$, and micrometeorites are larger, from $\sim 25 \mu \mathrm{m}$ to $\sim 500 \mu \mathrm{m}$.

Recognizing asteroidal from cometary dust is a challenge. So far two families of interplanetary dust of cometary origin have been tentatively identified both in the IDP and micrometeorite collections. 


\subsubsection{IDPs}

Since 1981, NASA has been collecting interplanetary dust particles (IDPs) in the stratosphere, between 17-19 km altitude [38]. IDPs are collected using NASA stratospheric planes (U2 and ER2) holding foldable collector plates covered with a layer of high viscosity silicon oil, over flight durations from $30 \mathrm{~h}$ to $65 \mathrm{~h}$. The fluffiest particles preferentially accumulate at these altitudes, due to their very low densities, and they get trapped in the sticky silicon oil when encountering the collector plates. Once back at the IDP curatorial facility at the NASA Johnson Space Center in Houston (TX-USA), the collectors are open and all particles are recovered and preliminary classified (http://curator.jsc.nasa.gov/dust/).

The IDPs have sizes ranging from 1 to $<50 \mu \mathrm{m}$, most particles being in the $\sim 2-15 \mu \mathrm{m}$ size range. They can be classified into two main categories, chondritic (i.e. showing a bulk chemical composition compatible with the average chondrite composition), and non chondritic IDPs (e.g. large single crystals of Fe-sulphide minerals, or silicates including refractory minerals) [e.g. 39-41]. Chondritic IDPs are characterized by their mineralogy, as deduced from they IR spectra (Olivine-, Pyroxene-, or LayerLattice-Silicate- dominated), or by their textures: (i) chondritic porous (CP, Figure 3 left), (ii) chondritic filled (less porous than CP IDPs), and (iii) chondritic smooth IDPs (CS, Figure 3 right) [see 42, and references therein].

The mineralogy of chondritic porous (CP) IDPs mainly consists of anhydrous crystalline phases (mostly Mg-rich olivines, pyroxenes and low-Ni Fe sulphides [42]), as well as primitive glassy components called Glass Embedded with Metals and Sulfides (GEMS) that could be of interstellar origin [43-47]. The mineralogy of CP IDPs is compatible with that of comets Halley and Hale-Bopp (e.g. [48] and references therein), and they are rich in carbonaceous matter (from $\sim 5$ to $\sim 45 \mathrm{wt} \%$, [49]). Some of these particles exhibit elevated D/H ratios [50-53]. It has been proposed that a large proportion (if not all) of CP IDPs could be of cometary origin (e.g. [54, 55] and references therein). Large isotopic anomalies interpreted as presolar interstellar signatures have been found in IDPs, both in the organic matter and in the mineral components, including GEMS and silicates [53, 56-58].
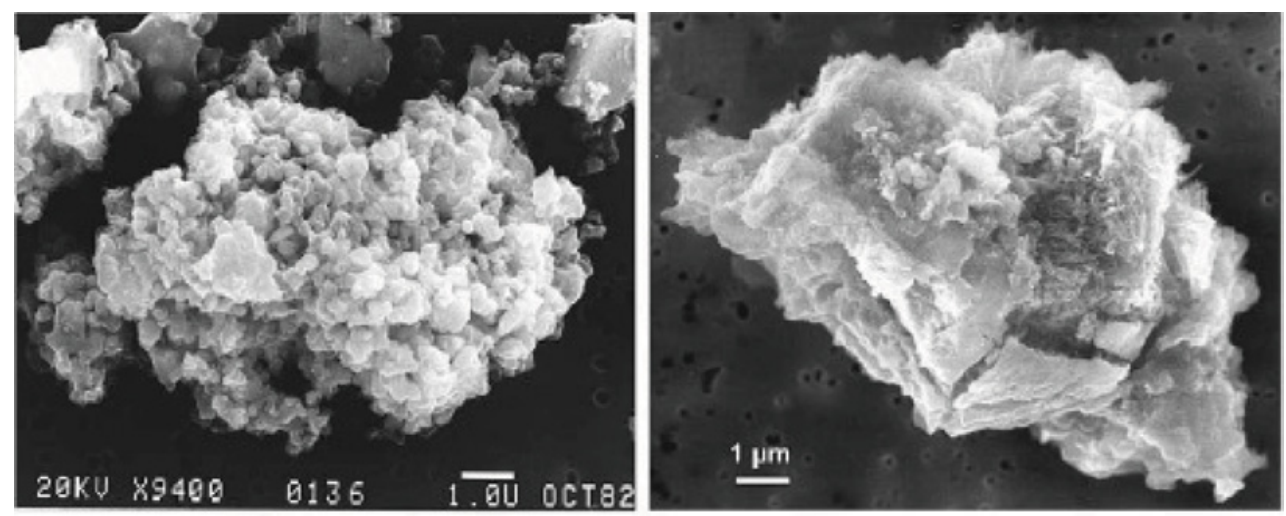

Figure 3. Secondary electron micrographs of : (left) a chondritic porous (CP) anhydrous IDP; and (right) a chondritic smooth (CS) hydrated IDP. From [42].

\subsubsection{Antarctic micrometeorites}

Micrometeorites are interplanetary dust particles collected at the Earth's surface. They span a size range complementary to that of IDPs, as they are recovered with sizes ranging from $\sim 20 \mu \mathrm{m}$ up to $\sim 1 \mathrm{~mm}$ (very large particles are rare in the flux, and the largest (rare) unmelted particles recovered have sizes around 500-700 $\mu \mathrm{m}$ ). Pioneering work from M. Maurette and co-workers has allowed the recovery of large numbers of unmelted micrometeorites from the polar ice caps, in Greenland [59, 60] and in 
Antarctica [61]. Micrometeorites have also been collected in ice and snow in Antarctica by Japanese and American teams (e.g. [62-65]).

Since 2000, micrometeorites are collected from clean snow near the CONCORDIA station, at Dome $\mathrm{C}$, in the central regions of Antarctica [4, 66, 67]. In addition to known types of particles (e.g. [68]), the CONCORDIA collection contains new objects including fine-grained fluffy particles and ultracarbonaceous grains that were absent from previous micrometeorite collections [3]. The micrometeorites from the CONCORDIA collection are uniquely preserved from terrestrial alteration.

Chondritic Antarctic Micrometeorites. Micrometeorites in the size range of Antarctic micrometeorites (Figure 4) are only related to a rare class of primitive meteorites, the carbonaceous chondrites [3, 68-72]. The origin (asteroidal, cometary, or both) of chondritic micrometeorites is still debated (e.g. [3, 68, 73, 74] and references therein). The STARDUST sample return has reinforced the hypothesis that chondritic micrometeorites may have mostly a cometary origin (see [35]).

The new family of fluffy fine-grained micrometeorites (Figure 4b) present in the CONCORDIA collection are samples having an external texture similar to that of CP-IDPs.
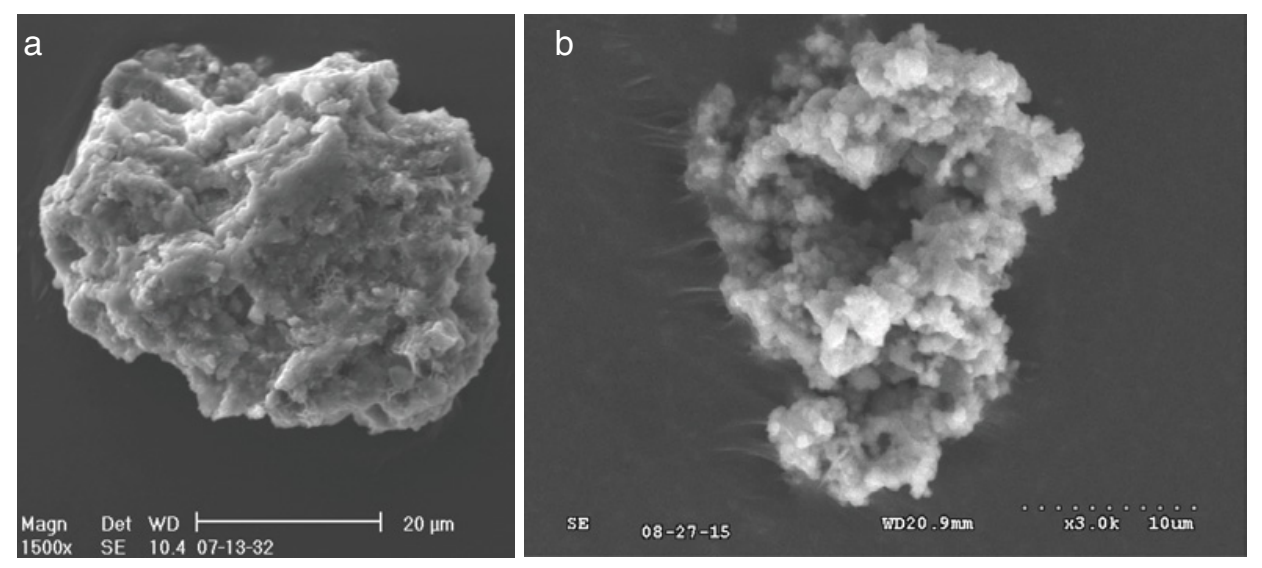

Figure 4. Scanning secondary electron micrographs of fragments of Antarctic micrometeorites (AMMs) from the CONCORDIA collection: (a) chondritic compact unmelted AMM; (b) fluffy fine-grained unmelted AMM.

Ultracarbonaceous Antarctic Micrometeorites: A new family of cometary grains. Micrometeorites dominated by organic matter were identified in the CONCORDIA collection (UCAMMS, for Ultracarbonaceous Antarctic Micrometeorites, Figure 5). These particles contain up to 85\% of organic matter in volume, thus showing carbon contents up to 10 times that of the most C-rich carbonaceous chondrites [75-77]. Three such UCAMMs were also reported in a collection performed at Dome Fuji [78]. Such concentrations of carbonaceous matter are comparable with that of the most C-rich IDPs $[79,80]$, and compatible with CHON grains detected in comet Halley by the Giotto and Vega spatial missions in 1986 [81, 82].

\section{BEFORE/AT THE FORMATION OF THE SOLAR SYSTEM}

Meteorites have retained some clues concerning the protosolar cloud that collapsed to form the solar system. They still contain some minute amount of interstellar matter that survived the early accretion processes in the protoplanetary disk. Among these, presolar mineral grains are found in meteorite matrices, and the presence of short-lived radionuclides (SLR) has been demonstrated at the time of CAI formation. 


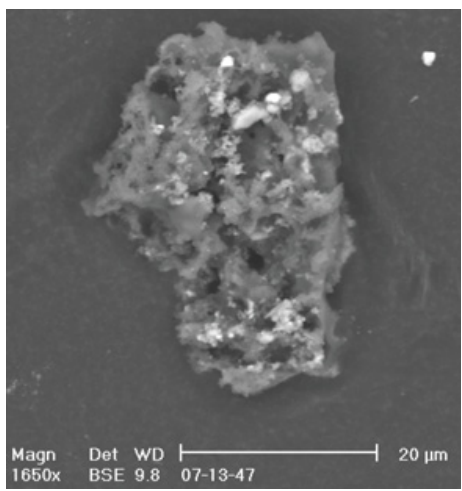

Figure 5. Backscattered electron micrograph of a fragment of CONCORDIA Ultracarbonaceous Antarctic Micrometeorite (UCAMM). All dark grey patches are constituted of organic matter. Brighter flakes are silicates or Fe-Ni sulphides.

\subsection{Ashes of previous star formation: Presolar grains}

The material that constituted the protosolar molecular cloud has been transformed by physico-chemical processes in the solar nebula. Isotopic studies of meteorites and cosmic dust using secondary ion mass spectrometry (SIMS and NanoSIMS [83-85]) have allowed recognizing a small fraction of this presolar dust from the local interstellar medium (ISM) that survived the accretion processes in the solar system (see [86-88] and Table 2). These grains are characterized by large isotopic anomalies of their major or minor (or even trace) elements. Most of these isotopic anomalies cannot be explained by physicochemical processes occurring in the solar system.

Table 2. Types and abundances of presolar grains identified in meteorites and cosmic dust. From [87, 89]. The presolar origin of nanodiamonds is debated.

\begin{tabular}{ccc}
\hline Grain Type & Size & Abundance \\
\hline Nanodiamonds & $2 \mathrm{~nm}$ & $1000-1400 \mathrm{ppm}$ \\
Amorphous silicates & $0.2-0.5 \mu \mathrm{m}$ & $<20-3600 \mathrm{ppm}$ \\
Forsterite and enstatite & $0.2-0.5 \mu \mathrm{m}$ & $<10-1800 \mathrm{ppm}$ \\
$\mathrm{SiC}$ & $0.1-0.5 \mu \mathrm{m}$ & $14-30 \mathrm{ppm}$ \\
Graphite & $1-20 \mu \mathrm{m}$ & $7-13 \mathrm{ppm}$ \\
Spinel $\left(\mathrm{MgAl}_{2} \mathrm{O}_{4}\right)$ & $0.1-20 \mu \mathrm{m}$ & $1.2 \mathrm{ppm}$ \\
Corundum $\left(\mathrm{Al}_{2} \mathrm{O}_{3}\right)$ & $0.2-3 \mu \mathrm{m}$ & $100 \mathrm{ppb}$ \\
$\mathrm{Si}_{3} \mathrm{~N}_{4}$ & $1-5 \mu \mathrm{m}$ & $1-20 \mathrm{ppb}$ \\
$\mathrm{TiO}_{2}$ & $\mathrm{n} . \mathrm{d}$. & $<10 \mathrm{ppb}$ \\
Hibonite $\left(\mathrm{CaAl}_{12} \mathrm{O}_{19}\right)$ & $1-5 \mu \mathrm{m}$ & $20 \mathrm{ppb}$ \\
\hline
\end{tabular}

In average, IDPs contain $\sim 300$ ppm of presolar grains. The largest amount of presolar grains $(\sim 1 \%)$ was recently identified in one IDP collected by NASA in April 2003 that may be associated with comet 26P/Grigg-Skjellerup [90].

The presolar origin of nanodiamonds is still debated [e.g. 91]. Silicon carbide grains (SiC) are not the most abundant presolar grains, but they were the first ones to be discovered in the acid-insoluble residue obtained after acid dissolution of whole rock fragments of meteorites. The most abundant presolar grains are silicates: amorphous silicates like GEMS (see section 2.3.1), and forsterite and enstatite minerals (the magnesian endmembers of the olivine and pyroxene solid solutions, respectively). They have been discovered by in situ NanoSIMS analyses of polished sections or crushed fragments of meteorites and 
cosmic dust (see [87] and references therein). Abundant silica grains showing extreme oxygen isotopic ratios were found in acid-dissolution residue of the Murchison meteorite, but their origin remains an open question [92].

The isotopic compositions of presolar grains give insights into the structure and processes in stars from the local ISM (e.g. [86, 88, 93]). Most SiC, graphite and silicate grains are thought to originate from low mass stars ( 0.7 - 3 solar mass) belonging to the Asymptotic Giant Branch (AGB), or from metal-poor stars [57, 94]. Grains from massive stars can exhibit excesses in ${ }^{28} \mathrm{Si},{ }^{44} \mathrm{Ti}$ and ${ }^{49} \mathrm{~V}$. Dust grains from massive stars are rare, like type $\mathrm{X} \mathrm{SiC}$ and $\mathrm{Si}_{3} \mathrm{~N}_{4}$ [86, 95]. Rare minerals have also been proposed to originate from supernova, like olivines [58], silicates [90], and maybe spinels [96].

\subsection{Short-lived radionuclides: A stellar (presolar) or nebular origin?}

Refractory inclusions (CAIs) in meteorites are among the first solids to have formed in the solar nebula. Their analyses showed that they contain the daughter elements of short-lived (less than a few million years) radioactive elements that decayed after the crystallization (i.e. isotopic closure) of these inclusions. The inferred abundance of these short-lived radionuclides (SLR) are, in most cases, far above that predicted by the chemical evolution of the galaxy. The most emblematic of these now extinct radionuclides is ${ }^{26} \mathrm{Al}$, which was first discovered in CAIs in 1976 [97].

The origin of these short-lived radionuclides can provide clues on the local physical and chemical conditions of the solar nebula and on its astrophysical environment. If they were homogeneously distributed in the early solar system, they provide high precision chronometers for the first millions of years of the solar system [98]. In the case of ${ }^{26} \mathrm{Al}$ and ${ }^{60} \mathrm{Fe}$, the energy generated by their decay could also help differentiating bodies of sufficient sizes. Since the discovery of ${ }^{26} \mathrm{Al}$, other extinct radioactivities have been found (Table 3) (see also [99, 100]).

Table 3. Short-lived radionuclides and corresponding half-lives identified in refractory inclusions, with representative literature references.

\begin{tabular}{ccccccccc}
\hline Radionuclide & ${ }^{26} \mathrm{Al}$ & ${ }^{53} \mathrm{Mn}$ & ${ }^{41} \mathrm{Ca}$ & ${ }^{10} \mathrm{Be}$ & ${ }^{36} \mathrm{Cl}$ & ${ }^{182} \mathrm{Hf}$ & ${ }^{60} \mathrm{Fe} ?$ & ${ }^{7} \mathrm{Be} ?$ \\
\hline $\begin{array}{c}\mathrm{T}_{1 / 2}(\mathrm{Ma}) \\
\text { Refs. }\end{array}$ & 0.72 & 3.7 & 0.1 & 1.5 & 0.3 & 8.9 & 1.5 & 53.2 days \\
{$[97,101-104]$} & {$[105-107]$} & {$[108,109]$} & {$[110,111]$} & {$[112]$} & {$[113-116]$} & {$[117-120]$} & {$[111]$} \\
\hline
\end{tabular}

Two main scenarios have been investigated to explain the presence of these extinct radionuclides in the protoplanetary disk: a nebular process, by irradiation of CAI precursors by the young Sun in the early protosolar disk, in the frame of the X-wind model proposed by Shu et al. [121] [e.g. 122-125]; or a last minute injection of stellar products (formed by thermal nucleosynthesis) in the parent molecular cloud of the solar system (e.g. [126-128]).

${ }^{26} \mathrm{Al}$ was homogeneously distributed throughout the fraction of the protoplanetary disk that eventually formed the terrestrial planets [129]. Energetic constraints preclude a massive production of SLR by irradiation in the early solar system. In particular, it does not seem possible to produce the early solar system ${ }^{26} \mathrm{Al}$ budget by any irradiation scenario [130]. Irradiation can however produce both ${ }^{10} \mathrm{Beand}{ }^{41} \mathrm{Ca}$ at levels compatible with their abundances inferred from the CAI isotopic compositions [108-110, 130].

The early solar system abundances of ${ }^{26} \mathrm{Al}$ and ${ }^{41} \mathrm{Ca}$ can be explained by the injection of stellar nucleosynthetic products originating from a Wolf-Rayet star that escaped from its parent cluster and interacted with its surrounding cold and dense molecular cloud [128].

The explosion of the Wolf-Rayet star as a supernova may have triggered the collapse of the protosolar cloud and the formation of the solar system.

The presence of ${ }^{60} \mathrm{Fe}$ in primitive meteorites in excess to abundances expected from galactic evolution is still debated. Stellar nucleosynthesis is required to produce efficiently ${ }^{60} \mathrm{Fe}$ [127], however, 
the distribution of ${ }^{60} \mathrm{Fe}$ was probably heterogeneous in the protosolar disk and its bulk abundance is therefore difficult to assess [120].

Extinct radioactivities in primitive meteorites may thus have recorded both the existence of energetic irradiation in the vicinity of the protosun and a late injection of stellar nucleosynthesis products in the protosolar cloud $[128,131]$.

\section{DATING THE FORMATION OF THE SOLAR SYSTEM}

CAIs are believed to be the most ancient solids of the solar system [8, 132]. Their age inferred by radioactive clocks are taken as the time of formation of the Solar System.

There are long-lived (e.g U-Pb, Pb-Pb, $\mathrm{T}_{1 / 2} \sim \mathrm{Ga}$ ) and short-lived (e.g ${ }^{26} \mathrm{Al}-{ }^{26} \mathrm{Mg},{ }^{182} \mathrm{Hf}-{ }^{182} \mathrm{~W}$, $\left.\mathrm{T}_{1 / 2} \sim 1 \mathrm{Ma}\right)$ radio-chronometers that can give complementary ages. Isotopic compositions measured nowadays are taken as representative of that at the time of isotopic closure (e.g. crystallisation of the solids in the protoplanetary disk). Contradictions between ages measured by different techniques can sometimes be related to heterogeneities of the isotopic reservoirs, later perturbation of the isotopic system, uncertainty in the determination of the initial Daughter/Parent ratio... (e.g. [133-135]).

The first estimation for the age of the solar system goes back to 1956 , with a ${ }^{207} \mathrm{~Pb}^{206} \mathrm{~Pb}$ age of $4.55 \pm 0.07 \mathrm{Ga}$ measured in the Canyon Diablo meteorite [136]. Refinements in analytical procedures now allow measuring $\mathrm{Pb}-\mathrm{Pb}$ ages with accuracy better than $1 \mathrm{Ma}$. The oldest age reported recently in a CAI is $4568.5 \pm \mathbf{0 . 2}$ Ma [137].

Dating the formation of solids in the first million years can be probed by analysing CAIs and chondrules (e.g [129, 138-142]). The evolution of small planetesimals can be studied with iron meteorites, which are thought to originate from the core of differentiated asteroids $[113,115,116,143$, $144]$.

From these studies, chondrules are estimated to form about 1-2 Ma after CAIs [134, 138], and all evidences point toward a very rapid formation and differentiation of small planetesimals, within the first millions of years after CAI formation.

As a summary, the accretion of solids, formation of CAIs and chondrules and differentiation of small planetesimals happened very rapidly, in the first millions of years of the solar system.

\section{FIRST EPOCH: THE PROTOPLANETARY DISK}

\subsection{Nebular processes vs. interstellar heritage in the protoplanetary disk}

Meteorites from the asteroid belt provide samples from the inner regions of the solar system (i.e. the region of terrestrial planets). The dust and gas from the inner regions may have been processed by high temperature events in the protoplanetary disk. The formation of CAIs and chondrules (and of their sub-components) in meteorites are representative examples of the results of such processes.

On the contrary, comets have formed at large heliocentric distances at very low temperatures. In particular, they were expected to contain large amounts of small dust particles of interstellar origin already present in the protosolar cloud, hence the naming of the NASA "STARDUST" mission to comet Wild 2.

The clear distinction between asteroids from the inner regions and comets from the outer regions of the solar system is now questioned by the results of STARDUST samples, and by the study of cosmic dust particles.

\subsubsection{Cosmic dust as a representative sampling of interplanetary matter?}

Cosmic dust in the size range of micrometeorites $(<500 \mu \mathrm{m})$ currently represents the dominant input of extraterrestrial matter accreted by the Earth, about 1000 times more than meteorites [37, 62, 145]. One 
of the most striking results of micrometeorite research consists in their relationship to carbonaceous chondrites that represent only $4 \%$ of the meteorites (e.g. [69, 70, 146, 147]). In other words, $96 \%$ of all meteorite types are not represented in the incoming cosmic dust flux.

The question is thus raised about the samples that best represent interplanetary matter. Reasons to believe that cosmic dust could be these samples are listed below:

- The dynamical evolution of cosmic dust in interplanetary space is less biased than that of meteorites. It is dominated by non-gravitational forces like Poynting-Robertson drag [148], whereas meteorites are delivered to Earth as a result of interactions with resonances, and their accretion is biased through gravitational focusing by the Earth [149].

- The high proportion of carbonaceous-chondrite like objects (related to C-type asteroids) in the cosmic dust population $(>80 \%$ [e.g. $[69,70,146,147])$ better agrees with the proportions of C-type $(>55 \%)$ over S-type $(<20 \%)$ asteroids [150]) than that in the meteorite collections $(\sim 5 \%)$. The meteorite collections could in fact under-represent the carbonaceous chondrites (CC) with regard to ordinary chondrites (linked to S-type asteroids [12, 16, 151, 152]), as these fragile CC meteorites may be preferentially destroyed during atmospheric entry and by weathering at the Earth's surface before recovery (e.g. [153]).

- There are also evidences that the flux of micrometeorites did not change in composition as a function of time [72, 154-156] or toward smaller sizes [157, 158].

This view was recently challenged by new dynamical models that favour a preferential formation of large amounts of dust from Jupiter family comets that could explain the high abundance of carbonaceous-chondrite-like objects in the micrometeorite collections [35, 159]. This work would thus imply that most (if not all) micrometeorites with sizes $<500 \mu \mathrm{m}$ are of cometary origin, and thus that the mineral components of cometary material are close to that of carbonaceous chondrites [3] (a result also suggested by analyses of STARDUST samples - [e.g. 1]).

Larger micrometeorites $(>500 \mu \mathrm{m})$ collected in the Transantarctic Mountains [160] seem to form a population that is intermediary between micrometeorites with sizes $<500 \mu \mathrm{m}$ and meteorites, as large amounts of ordinary chondrite-like material ( 30\% [161]) and objects from differentiated bodies [162] are present in this collection.

In the following we present the limits of the classical distinction between inner and outer regions of the protoplanetary disk.

\subsubsection{Tracing high temperature processes in the protoplanetary disk}

The composition of the non-volatile elements from the early solar nebula has been preserved in the Sun's photosphere, and in primitive CI meteorites, over a large range of abundances (Figure 6).

Deviations from this composition in meteorites are interpreted as produced by processes happening in the protoplanetary disk (e.g. chondrule formation) or by alteration processes in the meteorite parent body (e.g. hydrothermal alteration, differentiation).

Results from Wild 2 samples (STARDUST) show that the chemical composition of dust from comet Wild 2 is similar within a factor of 2 to the CI composition for most major and minor elements (Figure 7).

For non-volatile elements, there is thus no large chemical fractionation between the inner and outer regions of the solar system.

Condensation sequence and formation of chondrules. Meteorites contain both high and low temperature components, in the form of minerals and organic or alteration compounds, respectively.

Refractory inclusions in meteorites (CAIs) were the first solid phases formed at high temperatures $(\mathrm{T}>1200 \mathrm{~K})$ in the protoplanetary disk. Equilibrium thermodynamical calculations have shown that condensation mechanisms from a gas of solar composition at various total pressures (typically from $10^{-6}$ to $10^{-1}$ bar) can explain the formation of some CAI components [e.g. 166-168, and references therein] (Figure 8). 


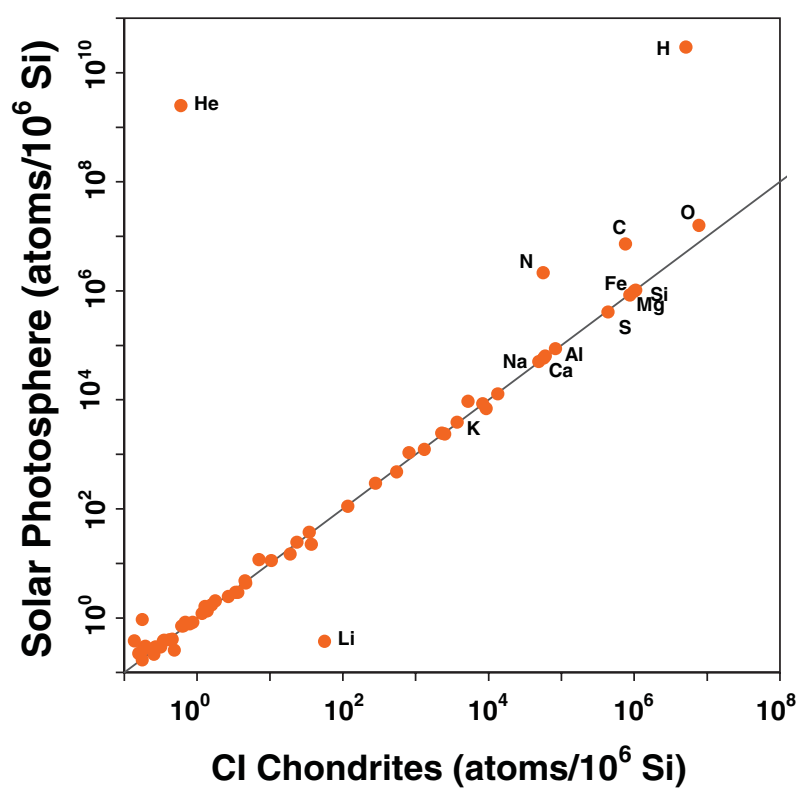

Figure 6. Composition of the solar photosphere compared to that of Ivuna type carbonaceous chondrites (CI chondrites). Data are normalised to $\log \mathrm{N}(\mathrm{H})=12$ in the Sun photosphere (from [7]).

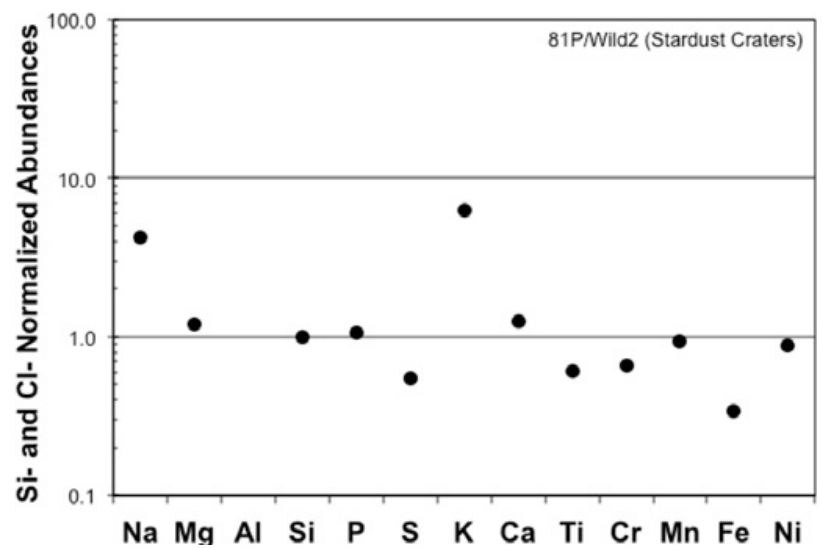

Figure 7. Comparison of the chemical composition of STARDUST samples (Comet Wild 2) measured in craters from $\mathrm{Al}$ foils in the STARDUST collector, normalized to Si and CI chondrites. Data from [163-165].

Classical models of chondrule formation invoke high temperature heating (up to $\mathrm{T}>1800 \mathrm{~K}$ ) of dust aggregate precursors for minutes to hours, and that cooled at different cooling rates (from $\sim 10$ to $1000 \mathrm{~K} / \mathrm{h}$ ) in order to reproduce the different textures observed (see [170, 171] for reviews). The porphyritic textures are the most difficult to reproduce, and suggest important reprocessing of chondrules. The lack of large isotopic fractionation of volatile elements in chondrules suggests that the vapour evaporating from chondrules did not escape the chondrule-forming region (i.e. chondrules formed in a closed system). Modelling suggest that this region extended over $\sim 1000 \mathrm{~km}$ or more, with a high density of chondrules ( $\sim 1$ to 10 chondrules per cubic meter), which means that the chondrule forming region was in a high gas density, hence near the midplane of the protoplanetary disk (e.g. $[172,173])$. The currently favoured hypothesis to get the necessary energy to melt the dust aggregates 


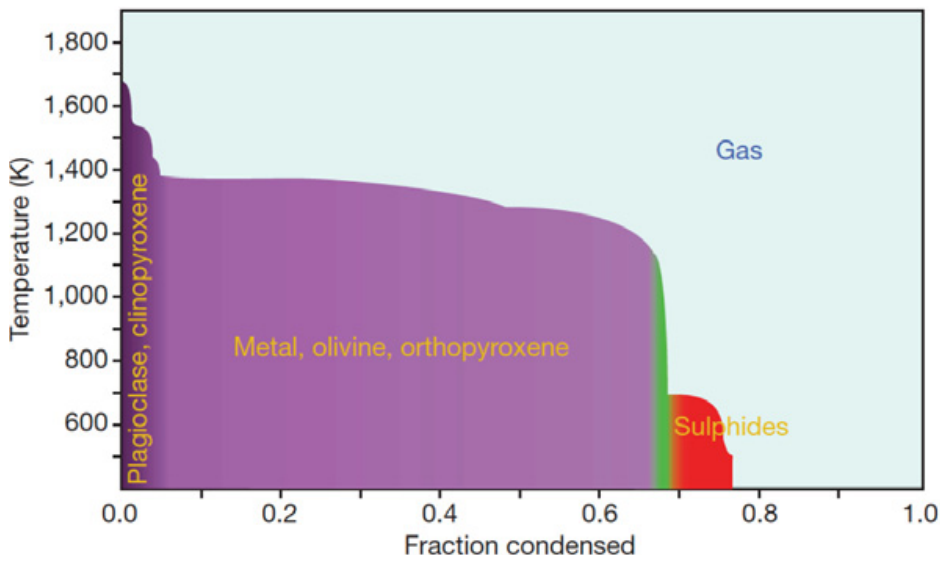

Figure 8. Mineral condensation sequence from a gas of solar composition. The first minerals to condense (left of diagram) are constituents of the refractory inclusions or CAIs (Ca-Al-rich inclusions) in meteorites. From [169].

involves shock waves triggered by gravitational instabilities [173, 174], but this field of research is still being explored. In such regions with high dust densities, chondrules may have coalesced into larger bodies ([175] and references therein).

Recent studies support the existence of a link between Type I chondrules and planetesimal formation. Libourel et al. showed that olivine and pyroxene minerals from Type I chondrule can not originate from the crystallisation of the same silicate melt [176-178]. Olivines first crystallized from the melt, and pyroxenes on the edge of the chondrules later formed by interaction of these olivines with protosolar $\mathrm{SiO}$ gas (e.g. [176, 179, 180]). The olivines in Type I chondrules frequently show triple junctions typical of textures observed in terrestrial mantle rocks, suggesting that Type I chondrules actually originate from the mantle of differentiated asteroids [176, 177]. This model supports a very fast evolution of the solar system in the first million years, with differentiation as a very early process, as seen by the datation of separated meteorite components.

Olivine and pyroxene abundances: A tracer of cometary origin? Remote sensing analyses have shown the presence of Mg-rich olivines and pyroxenes in comets (e.g. [28]). Investigation of Comet Halley in 1986 showed that in addition to Mg-rich olivines and pyroxenes, Fe sulphides and rare $\mathrm{Fe}$ metal grains are present, embedded in an omnipresent carbonaceous matter. The so-called "CHON" particles, showing a dominant signature of these 4 elements ( $\mathrm{H}, \mathrm{C}, \mathrm{N}$ and $\mathrm{O})$, are always mixed with minor amounts of minerals [25-27, 81, 181-184]. Mineralogical investigations of ultracarbonaceous Antarctic micrometeorites (UCAMMs) show the same intimate mixing between primitive organic matter and small mineral assemblages (see Figure 9).

The olivine/pyroxene abundance ratio in UCAMMs is less than 1, a value much lower than that in meteorites, except in CR chondrites.

Mineralogical data from remote sensing analyses of comets are coherent with comet Halley results, showing the presence of mostly crystalline Mg-rich olivines and pyroxenes in about equal abundances (e.g. $[28,186])$.

Wild 2 cometary dust particles (STARDUST samples) contain high temperature minerals, including fragments of refractory inclusions and chondrules. A low olivine/pyroxene ratio $(\sim 1)$ is also observed in STARDUST samples [187-190]. The mineralogical and chemical composition of Wild 2 is related to that of primitive meteorites such as carbonaceous chondrites [1, 187, 190-193]. 


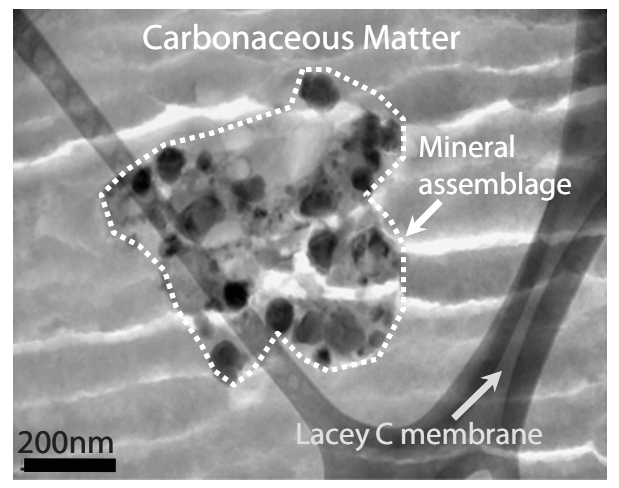

Figure 9. Transmission electron micrograph of an ultramicrotomed section of ultracarbonaceous Antarctic micrometeorites (UCAMMs) showing a mineral assemblage embedded in organic matter. From [185].

Several authors [194-197] report a mineralogical zonation in the abundance of olivine and pyroxenes in protoplanetary disks, with crystalline olivine dominating in the inner regions. This could be explained by olivine in the inner regions being formed from the annealing of amorphous pyroxene precursors, as suggested by the work of Roskosz et al. [198]. The olivine/pyroxene ratio could thus be used as an index of primitivity and a tracer for cometary origin [199] (see Figure 10).

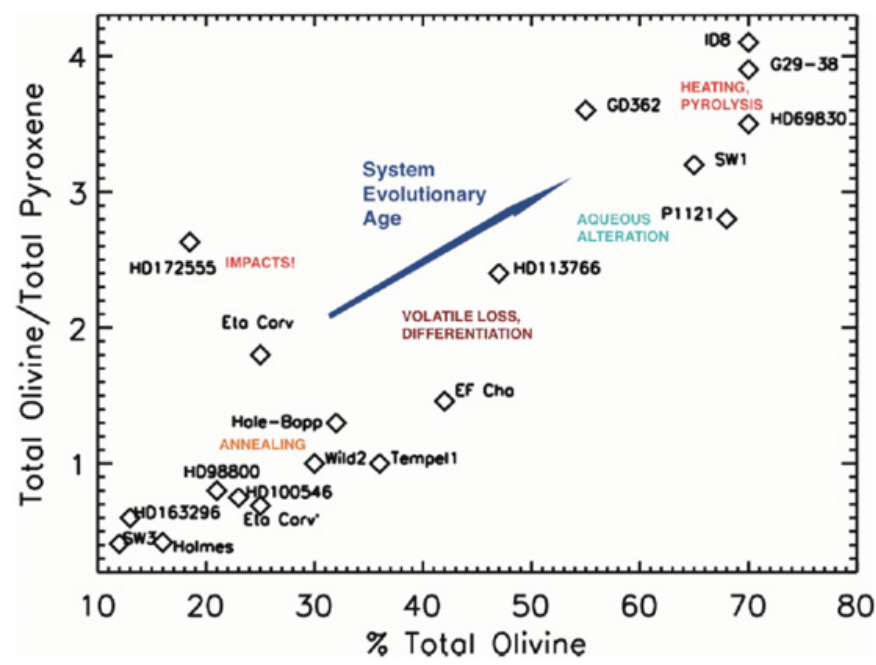

Figure 10. Olivine/pyroxene ratios in a diversity of objects. The comet data (SW3: 73P/Schwassmann-Wachmann 3, Holmes, Wild 2, Tempel 1, Hale-Bopp) lie on the primitive corner of the diagram. From [199].

Oxygen isotopic compositions of high temperature phases. The oxygen isotopic composition of minerals is a powerful tracer of high temperature processes, such as the crystallisation, evaporation of minerals, etc...In the 1970s, analysis of the isotopic composition of oxygen in whole rock meteorites by conventional mass spectrometry showed that the protoplanetary disk was isotopically heterogeneous for oxygen isotopes, each class of meteorites having an individual signature (e.g. [200, 201]) (Figure 11). Additionally, refractory inclusions (CAIs) in primitive meteorites systematically showed ${ }^{16} \mathrm{O}$ enrichments with regard to terrestrial values (e.g. [202, 203]). On an oxygen three isotope 

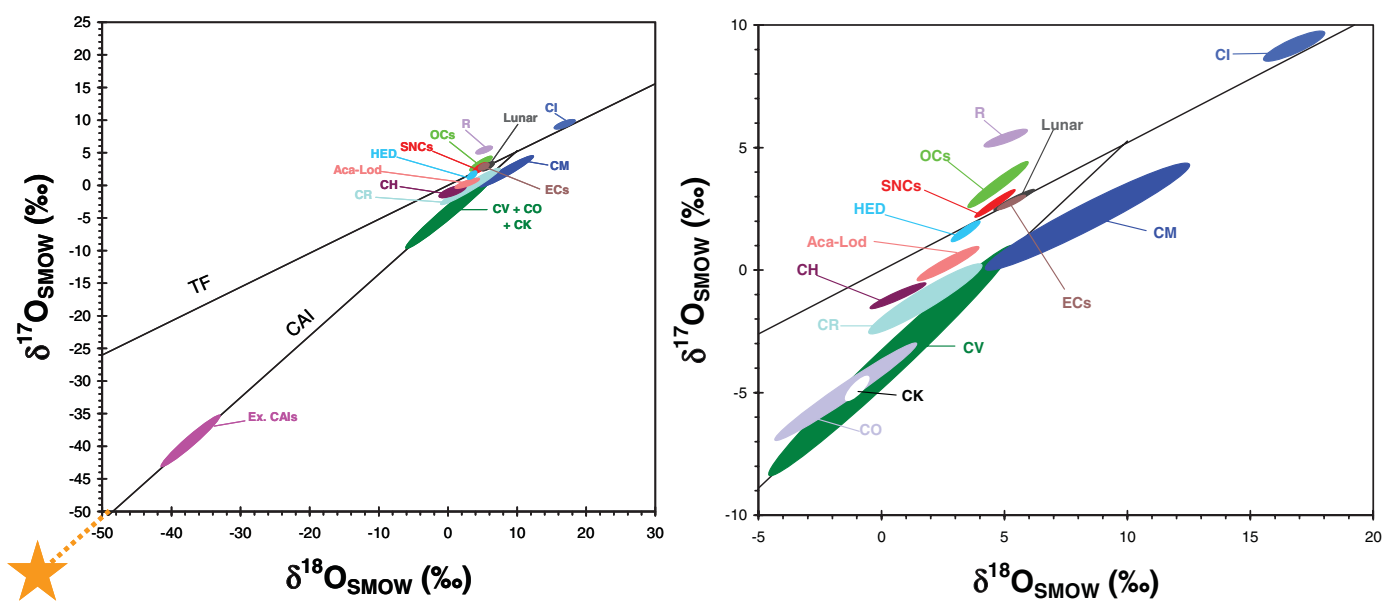

Figure 11. Oxygen three isotope plots showing the composition of meteorites, with a detailed view on the right. The yellow star on the left diagram represents the composition of the Sun [204]. See Table 1 for the definitions of meteorite types; et OCs: Ordinary chondrites, ECs : Enstatite chondrites, SNCs : Shergottites Nakhlites Chassignites - thought to come from Mars, HED : Howardites Eucrites Diogenites - possibly from asteroid Vesta, Aca-Lod: Acapulcoïtes-Lodranites). The terrestrial fractionation line - TF is shown for reference, as well as the line defined by the refractory minerals (CAI). A few CAI data are given as examples (Ex. CAIs). The $\delta$ notation corresponds to the relative difference in permil (L') of the isotopic ratios normalized to a terrestrial reference SMOW (Standard Mean Ocean Water). $\delta^{17,18} \mathrm{O}_{\text {SMOW }} \% o=\left[\left({ }^{17,18} \mathrm{O} /{ }^{16} \mathrm{O}_{\text {sample }} /{ }^{17,18} \mathrm{O} /{ }^{16} \mathrm{O}_{\text {SMOW }}\right)-1\right] \times 1000$. Meteorite data from [201, 203, 208-225].

plot, these ${ }^{16} \mathrm{O}$-rich values do not plot on the terrestrial fractionation line, but on a slope $\sim 1$ line, called the CAI line (Figure 11).

These CAI compositions are close to the Sun value. Recent analyses of solar wind (SW) samples returned by the GENESIS mission (NASA) conclude that the oxygen isotopic composition of the Sun is enriched in ${ }^{16} \mathrm{O}$ with regard to the Earth, at a level of $\sim 7 \%$ [204]. This ${ }^{16} \mathrm{O}$-rich composition of the Sun was also deduced from the analyses of SW implantation in lunar soils, although the results had been debated [205-207].

The oxygen isotopic ${ }^{16} \mathrm{O}$ anomaly thus in fact resides in the Earth and the rocky planets being depleted in ${ }^{16} \mathrm{O}$ compared to the Sun (that represents more than $99.8 \%$ of the solar system mass).

The processes leading to the distribution of isotopic compositions of oxygen in meteorites and rocky planets are not clearly established yet. Most physical processes fractionate the isotopes in a massdependent way, leading to data plotting on a slope $\sim 0.5$ line, like on Earth (terrestrial fractionation line - TF). The slope $\sim 1$ line (i.e. the CAI line) cannot be explained by such processes. The non-massdependent fractionation of $\mathrm{O}$ isotopes in meteorites requires a special mechanism that operated on a large scale. Deciphering that process(es) is by no means trivial, as oxygen represents the third most abundant element in the solar system, and the most abundant one in rocky material. Several scenarios are currently debated to explain the slope $\sim 1$ of the CAI line. A first hypothesis is the production of an ${ }^{16} \mathrm{O}$-depleted reservoir (later to be mixed with solar $\mathrm{O}$ ) by selective photodissociation (selfshielding) of CO molecules in the protosolar disk [226-228] or in the parent molecular cloud [229]. Experiments aiming at reproducing such isotopic effects by self shielding of $\mathrm{CO}$ are currently highly debated [230-234]. A second hypothesis refers to mass-independent isotopic fractionation processes involving molecular symmetry-dependent reactions acting in the solar nebula, like what is observed for terrestrial ozone [235-238]. Finally, a third hypothesis invokes heterogeneous chemical processes involving the formation of ${ }^{16} \mathrm{O}$-depleted $\mathrm{H}_{2} \mathrm{O}$ (via ozone formation) at the surface of interstellar grains in dense molecular clouds [239]. 

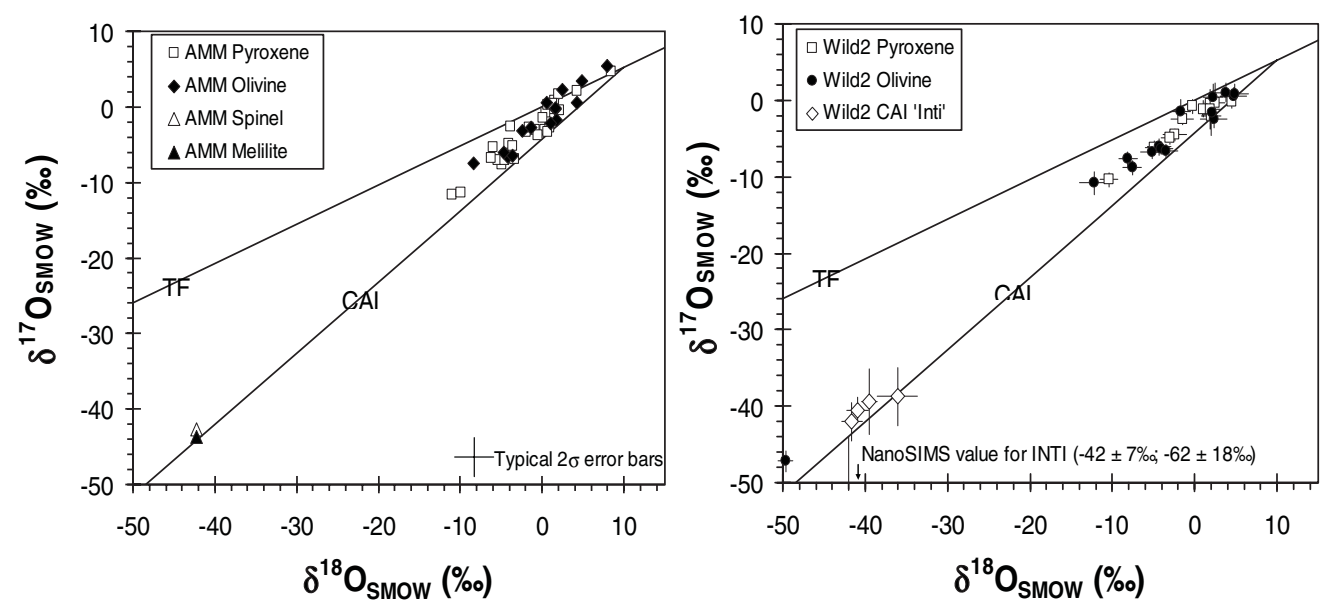

Figure 12. Isotopic composition of oxygen in Antarctic micrometeorites (left panel, from [147]) compared to that in Wild 2 (STARDUST) samples (right panel $[193,240]$ ).

The distribution of $\mathrm{O}$ isotopes in the protoplanetary disk is heterogeneous on a small scale defining localized $\mathrm{O}$ isotopes reservoirs, but there is not clear difference between that of asteroids (meteorites) and comets (STARDUST samples [190, 193, 240] and remote sensing analyses [e.g. 29, 241, and references therein]). Oxygen isotopic compositions of minerals from STARDUST samples have confirmed the similarity between Wild 2 minerals and that of primitive carbonaceous chondrite-like matter. In particular, the oxygen isotopic composition of Antarctic micrometeorites shows similarities with that of carbonaceous chondrites [147], and with STARDUST samples (Figure 12).

The oxygen isotopes being characteristic of meteorite classes and of mineral phases (like CAIs), deviations from the usual values can give insights into the evolution of mineral phases. Some CAIs could have sampled more than one $\mathrm{O}$ isotopic reservoir, thus recording a circulation in the early solar nebula (e.g. [242]).

\subsubsection{Low temperature processes in the protoplanetary disk}

This topic is more detailed in the chapter by L. Remusat in this volume.

Primitive volatiles and organic phases. Spectroscopic studies show the richness in volatile and organic species of comets (e.g. [29]). Comet Halley contains mineral particles embedded in a ubiquitous carbonaceous matter ("CHON" particles that only contain $\mathrm{C}, \mathrm{H}, \mathrm{O}, \mathrm{N}$ elements, mixed with a minor stony component) (e.g. [25-27, 81, 181-184]). We do not have samples of cometary volatiles on Earth, but we do have samples containing very primitive organic matter from the outer regions of the protoplanetary disk, the C-rich IDPs, and the ultracarbonaceous Antarctic micrometeorites (UCAMMs, see Figure 5 and Figure 9) [4, 185].

Organic compounds (amine, glycine, complex aromatic hydrocarbons) and carbonaceous phases (carbonaceous grains and nanoglobules) are present in comet Wild 2 (STARDUST) samples but not at levels expected from previous characterizations of comets [243-249]. This may be due to the fact that only solid phases were sampled in the aerogel, and that they were partially destroyed upon impact in the collector [e.g. 243].

The outer regions of the protoplanetary disk contain an important contribution of volatiles and carbon-rich phases, which could have either a nebular origin or be inherited from the local interstellar medium. Light element isotopes provide clues about the origin of these carbonaceous phases. 
Nebular vs. Interstellar origin: Light element isotopes. The isotopic compositions are tracers of physical and chemical conditions of the formation and evolution of materials. The hydrogen isotopic composition of cometary water has been measured for 6 comets so far: Halley [250, 251], Hyakutake [252], Hale-Bopp [253], C/2001 Q4 (NEAT) [254], C/2002 T7 (LINEAR) [255] and 8P/Tuttle [256]. The D/H ratio for cometary $\mathrm{H}_{2} \mathrm{O}$ is $\sim 3 \times 10^{-4}$, about twice the terrestrial value SMOW (Standard Mean Ocean Water, D/H = $115.76 \times 10^{-6}$ [257]). Other cometary volatiles are enriched in D; an emblematic example is HCN in comet Hale-Bopp that is about 15 times enriched in D with regard to the SMOW value [258].

The hydrogen isotopic composition of STARDUST samples shows moderate deuterium enrichments, with D/H ratios up to twice the terrestrial value. However, these low ratios are probably not representative of the $\mathrm{D} / \mathrm{H}$ values of comet Wild 2, since STARDUST samples are likely contaminated by terrestrial hydrogen in the aerogel [240].

The hydrogen isotopic composition has a heterogeneous distribution in the solar system. The atmosphere of the gaseous planets have formed by gravitational collapse of protosolar gas and have thus retained the primitive isotopic composition of the protosolar nebula that was depleted in D compared to SMOW (Figure 13). The molecular species $\left(\mathrm{H}_{2} \mathrm{O}, \mathrm{HCN}\right)$ in the cometary regions are more enriched in $\mathrm{D}$ than the inner regions of the solar system.

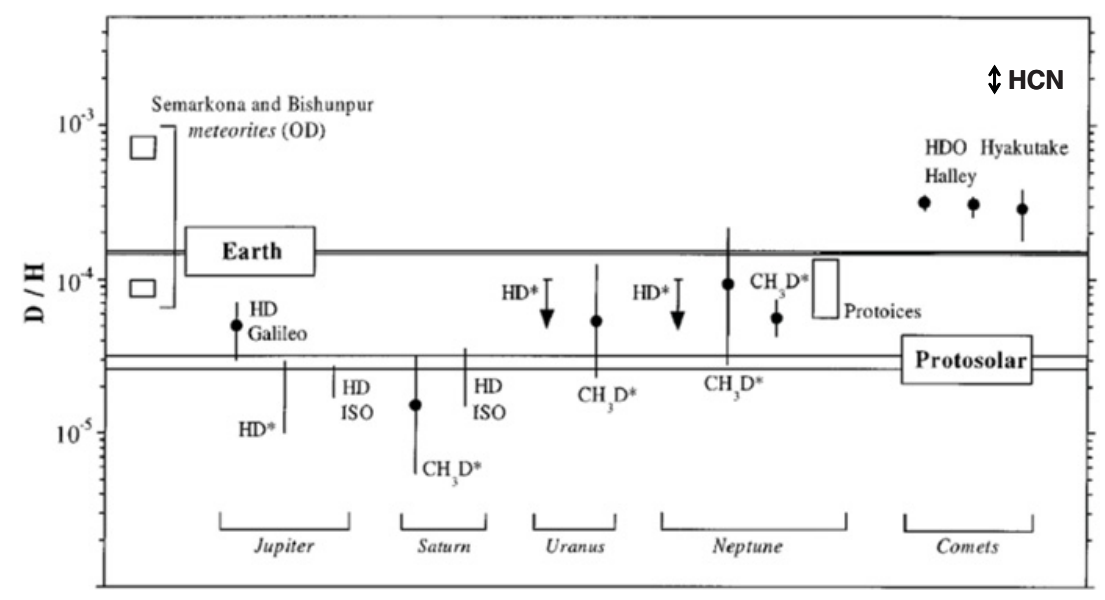

Figure 13. Variation of the D/H ratios in the solar system. Adapted from [252].

Large D enrichments in extraterrestrial matter are usually interpreted as an interstellar heritage. Indeed, ion-molecule reactions at very low temperatures in dense molecular clouds are expected to greatly enhance the $\mathrm{D} / \mathrm{H}$ ratio of $\mathrm{H}_{3}^{+}$ions [259]. However, recent work suggests that deuteration mechanism could also have occurred by the same ion-molecule reaction but within the solar nebula itself (e.g. [260]). The hydrogen isotopic composition of UCAMMs show extreme D enrichments over large areas $\left(>100 \mu \mathrm{m}^{2}\right)$, with $\mathrm{D} / \mathrm{H}$ ratios up to 10-30 times the SMOW value [4]. This isotopic composition is a signature of very primitive organic matter from the cold regions of the outer protoplanetary disk, and is not limited to hotspots of $1-2 \mu \mathrm{m}$ in size like usually observed in IDPs or meteorite IOM (e.g. [53, 261-263]). The association in UCAMMs of primitive organic matter with mineral phases (including crystalline minerals) that show evidence of nebular processing, suggest a deuteration of the organic matter within the solar system itself [4].

The $\mathrm{N}$ isotopic composition of the Sun has been measured in a primitive solar condensate (TiN, [264], in GENESIS samples [265, 266], and in the solar wind implanted in lunar soils [267]. These values are compatible with that measured by Galileo in the Jupiter atmosphere, and are depleted in ${ }^{15} \mathrm{~N}$ with regard to the terrestrial value by about 400 permil. The GENESIS measurements yield 
${ }^{15} \mathrm{~N} /{ }^{14} \mathrm{~N}=(2.26 \pm 0.03) \times 10^{-3}\left(\delta^{15} \mathrm{~N}=-384 \pm 8 \%\right.$ ). The terrestrial nitrogen isotopic composition $\left({ }^{15} \mathrm{~N} /{ }^{14} \mathrm{~N}=3.6765 \times 10^{-3}\right)$ is thus enriched by a factor of $\sim 1.6$ with regard to solar nitrogen. STARDUST samples do not show large $\mathrm{N}$ isotopic deviations from the terrestrial values, except in some carbonaceous phases [240, 245, 249]. The N isotopic compositions of $\mathrm{HCN}$ and $\mathrm{CN}$ in comets by remote sensing have been revisited; both $\mathrm{HCN}$ and $\mathrm{CN}$ are enriched in ${ }^{15} \mathrm{~N}$ by about a factor of 2 with regard to terrestrial value, $\mathrm{HCN}$ being the precursor molecule of $\mathrm{CN}$ [see 268-270].

Large-scale mechanisms are required to enrich the terrestrial planet region in ${ }^{15} \mathrm{~N}$. Possible scenarios include the addition of ${ }^{15} \mathrm{~N}$-rich presolar components, or low temperature isotopic exchange. Recent work suggests that mixing of several components is required to explain the observed $\mathrm{N}$ isotopic composition of organic matter in meteorites and in comets [271].

Carbon and sulphur isotopes in comets have isotopic compositions that are similar to that observed on Earth within errors [e.g. 29, 241, and references therein].

\subsection{Toward an asteroid-comet continuum}

Comets contain Mg-rich silicates, olivines and pyroxenes, identified by infrared spectroscopy (e.g. [272]). STARDUST samples showed that Wild 2 cometary dust also contain very high temperature phases like CAIs and chondrules [1]. More than $50 \%$ of Wild 2 material recovered by STARDUST (i.e. mostly the fraction $>2 \mu \mathrm{m}$, as the finer matrix was mostly destroyed during the collection impact) was processed in the inner regions of the solar system [273, 274]. The presence of high temperature phases (formed or severely processed close to the protosun) in the comet forming regions requires large scale radial mixing mechanism(s) in the early solar system.

Since both CAIs and chondrules have been found in STARDUST samples, this mechanism(s) had to operate for at least a few million years, as chondrules formed a few million years after CAIs $[1,187,190]$. Several models have been proposed to explain this radial transport, by viscous diffusion by turbulence [275, 276], by jets [277], or radiation pressure processes [278]. Other evidences for transport in the protoplanetary disk are given by the oxygen isotopic composition of high temperature phases (e.g. [242]), as well as by the hydrogen isotopic composition of low temperature phases [262].

Comet Wild 2 present similarities with primitive meteorite matter (carbonaceous chondrites), strongly supporting the hypothesis of a continuum between primitive asteroids and cometary matter. In fact, the outer asteroid belt contains objects that present a cometary activity [279], reinforcing the concept of this continuum.

Cosmic dust particles, in the form of micrometeorites [4] and primitive IDPs [55] are privileged objects to study this continuum between primitive asteroids and comets.

The work on UCAMMs is part of the $\mathrm{PhD}$ thesis of Elena Dobrică who made significant contributions in the characterization of this new family of cometary particles, in collaboration with H. Leroux, E. Quirico and J.-N. Rouzaud. Michel Maurette was a pioneer in collecting polar micrometeorites and interpreting the data for the formation of the solar system and for exobiological implications. Gero Kurat had a crucial role in micrometeorite research; he is deeply missed. Elena Dobrică, Jean Duprat, Eric Quirico and Dominique Bockelée-Morvan made a critical and fruitful reading of a first version of this manuscript. Jean Duprat and Matthieu Gounelle are important companion dusters. This work was supported by CNRS IN2P3, INSU (PNP), IPEV, ANR Jeunes Chercheurs "Micromet", CNES, and FP6 RTN Marie Curie "ORIGINS".

\section{References}

[1] D. Brownlee, et al., Science 314, 1711-1716 (2006)

[2] E. Grün, H.A. Zook, H. Fechtig and R.H. Giesse, Icarus 62, 244-272 (1985) 
[3] E. Dobrică, C. Engrand, J. Duprat, M. Gounelle, H. Leroux, E. Quirico and J.N. Rouzaud, Meteoritics Planet. Sci. 44, 1643-1661 (2009)

[4] J. Duprat, et al., Science 328, 742-745 (2010)

[5] S. Pizzarello, G.W. Cooper and G.J. Flynn, In Meteorites and the Early Solar System II, 625-651 (2006)

[6] A.N. Krot, K. Keil, C.A. Goodrich, E.R.D. Scott and M.K. Weisberg, In Meteorites, Comets and Planets: Treatise on Geochemistry, 1 83-128 (2005)

[7] K. Lodders, In Principles and Perspectives in Cosmochemistry, 379-417 (2010)

[8] M. Christophe Michel-Levy, Bulletin de la Société francaise de Minéralogie et de Cristallographie 91, 212-214 (1968)

[9] E.R.D. Scott and A.N. Krot, In Meteorites, Comets and Planets: Treatise on Geochemistry, 1 143-200 (2005)

[10] G.J. MacPherson, D.A. Wark and J.T. Armstrong, In Meteorites and the Early Solar System, 746-807 (1988)

[11] A.J. Brearley, In Meteorites, Comets and Planets: Treatise on Geochemistry, 1247-268 (2005)

[12] A. Fujiwara, et al., Science 312, 1330-1334 (2006)

[13] J. Saito, et al., Science 312, 1341-1344 (2006)

[14] H. Yano, et al., Science 312, 1350-1353 (2006)

[15] M. Yoshikawa, J. Kawaguchi and H. Yano, Lunar Planet. Sci. XLI, \#2746 (2010)

[16] T. Nakamura, et al., Lunar Planet. Sci. XLII, \#1766 (2011)

[17] M. Ebihara, et al., Lunar Planet. Sci. XLII, \#1788 (2011)

[18] E. Anders, Icarus 24, 363-371 (1975)

[19] H.Y. McSween, Jr. and P.R. Weissman, Geochim. Cosmochim. Acta 53, 3263-3271 (1989)

[20] H. Campins and T.D. Swindle, Meteoritics Planet. Sci. 33, 1201-1211 (1998)

[21] M. Gounelle, A. Morbidelli, P.A. Bland, P. Spurny, E.D. Young and M. Sephton, In The Solar System Beyond Neptune, 525-541 (2008)

[22] M.K. Weisberg and H.C. Connolly, Lunar Planet. Sci. XXXIX, \#1981 (2008)

[23] M. Gounelle, P. Spurny and P.A. Bland, Meteoritics Planet. Sci. 39, \#5174 (2004)

[24] K. Lodders, Astrophys. J. 591, 1220-1247 (2003)

[25] J. Kissel, et al., Nature 321, 336-337 (1986)

[26] J. Kissel, et al., Nature 321, 280-282 (1986)

[27] E.K. Jessberger, A. Christoforidis and J. Kissel, Nature 332, 691-695 (1988)

[28] M.S. Hanner and J.P. Bradley, In Comets II, 555-564 (2004)

[29] D. Bockelée-Morvan, J. Crovisier, M.J. Mumma and H.A. Weaver, In Comets II, $391-423$ (2004)

[30] A.J. Westphal, A.L. Butterworth, C.J. Snead, N. Craig, D. Anderson, S.M. Jones, D.E. Brownlee, R. Farnsworth and M.E. Zolensky, Lunar Planet. Sci. XXXVI, 1908 (2005)

[31] A.J. Westphal, et al., Lunar Planet. Sci. XL, \#1786 (2009)

[32] A.J. Westphal, et al., Lunar Planet. Sci. XLI, \#2050 (2010)

[33] E. Grün, Ann.Geophys. 13, Supp. III, C708 (1995)

[34] J. Lasue, A.C. Levasseur-Regourd, N. Fray and H. Cottin, Astron. Astrophys. 473, 641-649 (2007)

[35] D. Nesvorny, P. Jenniskens, H.F. Levison, W.F. Bottke, D. Vokrouhlicky and M. Gounelle, Astrophys. J. 713, 816-836 (2010)

[36] S.G. Love and D.E. Brownlee, Science 262, 550-553 (1993)

[37] P.A. Bland, T.B. Smith, A.J.T. Jull, F.J. Berry, A.W.R. Bevan, S. Couldt and C.T. Pillinger, Mon. Not. R. Astron. Soc. 283, 551-565 (1996)

[38] D.E. Brownlee, Ann. Rev. Earth Planet. Sci. 13, 147-173 (1985)

[39] F.J.M. Rietmeijer, In Advanced Mineralogy. Mineral matter in space, mantle, ocean floor, biosphere, environmental managment, and jewelry, 3 22-28 (1998)

[40] K.D. McKeegan, Science 237, 1468-1471 (1987) 
[41] M.E. Zolensky, Science 237, 1466-1468 (1987)

[42] J.P. Bradley, In Meteorites, Comets and Planets: Treatise on Geochemistry, 1 689-711 (2005)

[43] J.P. Bradley, Geochim. Cosmochim. Acta 52, 889-900 (1988)

[44] F.J.M. Rietmeijer, In Proceedings 19th Lunar and Planetary Science Conference 19 513-521 (1989)

[45] W. Klöck and F.J. Stadermann, In Analysis of Interplanetary Dust, AIP Conf. Proc., 310 51-87 (1994)

[46] J.P. Bradley, Science 265, 925-929 (1994)

[47] J.P. Bradley, L.P. Keller, T.P. Snow, M.S. Hanner, G.J. Flynn, J.C. Gezo, S.J. Clemett, D.E. Brownlee and J.E. Bowey, Science 285, 1716-1718 (1999)

[48] M.S. Hanner and M.E. Zolensky, In Astromineralogy, 203-226 (2010)

[49] L.P. Keller, K.L. Thomas and D.S. McKay, In Analysis of Interplanetary Dust, AIP Conf. Proc., 310 159-164 (1994)

[50] E. Zinner, K.D. McKeegan and R.M. Walker, Nature 305, 119-121 (1983)

[51] K.D. McKeegan, R.M. Walker and E. Zinner, Geochim. Cosmochim. Acta 49, 1971-1987 (1985)

[52] K.D. McKeegan, Ion microprobe measurements of $\mathrm{H}, \mathrm{C}, \mathrm{O}, \mathrm{Mg}$ and $\mathrm{Si}$ isotopic abundances in individual interplanetary dust particles. Ph.D. thesis thesis. Washington Univ., St. Louis (1987)

[53] S. Messenger, Nature 404, 968-971 (2000)

[54] J.P. Bradley and D.E. Brownlee, Science 231, 1542-1544 (1986)

[55] H.A. Ishii, J.P. Bradley, Z.R. Dai, M. Chi, A.T. Kearsley, M.J. Burchell, N.D. Browning and F. Molster, Science 319, 447- (2008)

[56] C. Floss, F.J. Stadermann, J. Bradley, Z.R. Dai, S. Bajt and G. Graham, Science 303, 1355-1358 (2004)

[57] S. Messenger, L.P. Keller, F.J. Stadermann, R.M. Walker and E. Zinner, Science 300, 105-108 (2003)

[58] S. Messenger, L.P. Keller and D.S. Lauretta, Science 309, 737-741 (2005)

[59] M. Maurette, C. Hammer, D.E. Brownlee, N. Reeh and H.H. Thomsen, Science 233, 869-872 (1986)

[60] M. Maurette, C. Jéhano, E. Robin and C. Hammer, Nature 328, 699-702 (1987)

[61] M. Maurette, C. Olinger, M. Christophe, G. Kurat, M. Pourchet, F. Brandstätter and M. BourotDenise, Nature 351, 44-47 (1991)

[62] S. Taylor, J.H. Lever and R.P. Harvey, Nature 392, 899-903 (1998)

[63] S. Taylor, J.H. Lever and R.P. Harvey, Meteoritics Planet. Sci. 35, 651-666 (2000)

[64] T. Yada and H. Kojima, Antarctic Met. Res. 13, 9-18 (2000)

[65] T. Nakamura, T. Noguchi, T. Yada, Y. Nakamuta and N. Takaoka, Geochim. Cosmochim. Acta 65, 4385-4397 (2001)

[66] J. Duprat, C. Engrand, M. Maurette, M. Gounelle, G. Kurat and C. Hammer, In Dome C Astronomy and Astrophysics Meeting, 14 51-56 (2005)

[67] J. Duprat, C. Engrand, M. Maurette, G. Kurat, M. Gounelle and C. Hammer, Adv. Space Res. 39, 605-611 (2007)

[68] M.J. Genge, C. Engrand, M. Gounelle and S. Taylor, Meteoritics Planet. Sci. 43, 497-515 (2008)

[69] G. Kurat, C. Koeberl, T. Presper, F. Brandstätter and M. Maurette, Geochim. Cosmochim. Acta 58, 3879-3904 (1994)

[70] C. Engrand and M. Maurette, Meteoritics Planet. Sci. 33, 565-580 (1998)

[71] G.F. Herzog, S. Xue, G.S. Hall, L.E. Nyquist, C.Y. Shih, H. Wiesmann and D.E. Brownlee, Geochim. Cosmochim. Acta 63, 1443-1457 (1999)

[72] C. Engrand, K.D. McKeegan, L.A. Leshin, G.F. Herzog, C. Schnabel, L.E. Nyquist and D.E. Brownlee, Geochim. Cosmochim. Acta 69, 5365-5385 (2005)

[73] M. Maurette, In Comets and the Origin and Evolution of Life, 69-111 (2006)

[74] M.J. Genge, Geology 36, 687-690 (2008) 
[75] M.M. Grady and C.T. Pillinger, Geochim. Cosmochim. Acta 50, 255-263 (1986)

[76] J.F. Kerridge, Geochim. Cosmochim. Acta 49, 1707-1714 (1985)

[77] S. Pizzarello, Y. Huang, L. Becker, R.J. Poreda, R.A. Nieman, G. Cooper and M. Williams, Science 293, 2236-2239 (2001)

[78] T. Nakamura, T. Noguchi, Y. Ozono, T. Osawa and K. Nagao, Meteoritics Planet. Sci. 40 Suppl., \#5046 (2005)

[79] L.P. Keller, S. Messenger, G.J. Flynn, S. Clemett, S. Wirick and C. Jacobsen, Geochim. Cosmochim. Acta 68, 2577-2589 (2004)

[80] K.L. Thomas, G.E. Blanford, L.P. Keller, W. Klöck and D. McKay, Geochim. Cosmochim. Acta 57, 1551-1566 (1993)

[81] J. Kissel and F.R. Krueger, Nature 326, 755-760 (1987)

[82] M.E. Lawler and D.E. Brownlee, Nature 359, 810-812 (1992)

[83] G. Slodzian, In Advances in Electronics and Electron Physics, Supplement 13B 1-44 (1980)

[84] G. Slodzian, B. Daigne, F. Girard and F. Hillion (1991) A high resolution scanning ion microscope with parallel detection of secondary ions. In SIMS VIII. Wiley, Chicester.

[85] F. Hillion, B. Daigne, F. Girard and G. Slodzian (1993) A new high performance instrument: the Cameca NanoSIMS 50. In SIMS IX, pp. 294, Yokohama, Japan.

[86] E.K. Zinner, H.D. Holland and K.K. Turekian, In Meteorites, Comets and Planets: Treatise on Geochemistry, 17-40 (2005)

[87] S. Messenger, S. Sandford, D. Brownlee and H.Y. McSween, Jr., In Meteorites and the Early Solar System II, 187-208 (2006)

[88] M. Lugaro, Stardust from meteorites. An introduction to presolar grains. World Scientific., New Jersey, London, Singapore. pp. 209.(2005)

[89] G.R. Huss, A.P. Meshik, J.B. Smith and C.M. Hohenberg, Geochim. Cosmochim. Acta 67, 48234848 (2003)

[90] H. Busemann, A.N. Nguyen, G.D. Cody, P. Hoppe, A.L.D. Kilcoyne, R.M. Stroud, T.J. Zega and L.R. Nittler, Earth Planet. Sci. Lett. 288, 44-57 (2009)

[91] Z.R. Dai, J.P. Bradley, D.J. Joswiak, D.E. Brownlee, H.G.M. Hill and M.J. Genge, Nature 418, 157-159 (2002)

[92] J. Aléon, F. Robert, J. Duprat and S. Derenne, Nature 437, 385-388 (2005)

[93] D.D. Clayton and L.R. Nittler, Annual Rev. Astron. Astrophys. 42, 39-78 (2004)

[94] K. Nagashima, A.N. Krot and H. Yurimoto, Nature 428, 921-924 (2004)

[95] L.R. Nittler, et al., Astrophys. J. 453, L25 (1995)

[96] N. Dauphas, L. Remusat, J.H. Chen, M. Roskosz, D.A. Papanastassiou, J. Stodolna, Y. Guan, C. Ma and J.M. Eiler, Astrophys. J. 720, 1577-1591 (2010)

[97] T. Lee, D.A. Papanastassiou and G.J. Wasserburg, Geophys. Res. Lett. 3, 41-44 (1976)

[98] S.S. Russell, G. Srinivasan, G.R. Huss, G.J. Wasserburg and G.J. MacPherson, Science 273, 757762 (1996)

[99] G.J. Wasserburg, M. Busso, R. Gallino and K.M. Nollett, Nuclear Physics A 777, 5-69 (2006)

[100] M. Wadhwa, Y. Amelin, A.M. Davis, G.W. Lugmair, B. Meyer, M. Gounelle and S.J. Desch, Protostars and Planets V, 835-848 (2007)

[101] G.J. MacPherson, A.M. Davis and E.K. Zinner, Meteoritics 30, 365-386 (1995)

[102] M. Bizzarro, J.A. Baker and H. Haack, Nature 431, 275-278 (2004)

[103] M. Bizzarro, J.A. Baker and H. Haack, Nature 435, 1280 (2005)

[104] E.D. Young, J.I. Simon, A. Galy, S.S. Russell, E. Tonui and O. Lovera, Science 308, 223-227 (2005)

[105] J.-L. Birck and C.-J. Allegre, Geophys. Res. Lett. 12, 745-748 (1985)

[106] J.L. Birck and C.J. Allegre, Nature 331, 579-584 (1988)

[107] G.W. Lugmair and A. Shukolyukov, Geochim. Cosmochim. Acta 62, 2863-2886 (1998)

[108] G. Srinivasan, A.A. Ulyanov and J.N. Goswami, Astrophys. J. 431, L67-L70 (1994) 
[109] G. Srinivasan, S. Sahijpal, A.A. Ulyanov and J.N. Goswami, Geochim. Cosmochim. Acta 60, 1823-1835 (1996)

[110] K.D. McKeegan, M. Chaussidon and F. Robert, Science 289, 1334-1337 (2000)

[111] M. Chaussidon, F. Robert and K.D. McKeegan, Geochim. Cosmochim. Acta 70, 224-245 (2006)

[112] Y. Lin, Y. Guan, L.A. Leshin, Z. Ouyang and D. Wang, Proceedings of the National Academy of Science 102, 1306-1311 (2005)

[113] T. Kleine, C. Münker, K. Mezger and H. Palme, Nature 418, 952-955 (2002)

[114] T. Kleine, H. Palme, K. Mezger and A.N. Halliday, Science 310, 1671-1674 (2005)

[115] T. Kleine, M. Touboul, B. Bourdon, F. Nimmo, K. Mezger, H. Palme, S.B. Jacobsen, Q.-Z. Yin and A.N. Halliday, Geochim. Cosmochim. Acta 73, 5150-5188 (2009)

[116] Q. Yin, S.B. Jacobsen, K. Yamashita, J. Blichert-Toft, P. Télouk and F. Albarède, Nature 418, 949-952 (2002)

[117] S. Mostefaoui, G.W. Lugmair, P. Hoppe and A. El Goresy, New Astron. Rev. 48, 155-159 (2004)

[118] S. Tachibana and G.R. Huss, Astrophys. J. 588, L41-L44 (2003)

[119] S. Mostefaoui, G.W. Lugmair and P. Hoppe, Astrophys. J. 625, 271-277 (2005)

[120] G. Quitté, A. Markowski, C. Latkoczy, A. Gabriel and A. Pack, Astrophys. J. 720, 1215-1224 (2010)

[121] F.H. Shu, S. Shang, M. Gounelle, A.E. Glassgold and T. Lee, Astrophys. J. 548, 1029-1050 (2001)

[122] T. Lee, F.H. Shu, H. Shang, A.E. Glassgold and K.E. Rehm, Astrophys. J. 506, 898-912 (1998)

[123] M. Gounelle, F.H. Shu, H. Shang, A.E. Glassgold, K.E. Rehm and T. Lee, Astrophys. J. 548, 1051-1070 (2001)

[124] M. Gounelle, M. Chaussidon and T. Montmerle, Comptes Rendus Geoscience 339, 885-894 (2007)

[125] C. Fitoussi, et al., Phys. Rev. C 78, 044613 (2008)

[126] S.S. Russell, M. Gounelle and R. Hutchison, Royal Soc. London Phil. Trans. A 359, 1991-2004 (2001)

[127] M. Bizzarro, D. Ulfbeck, A. Trinquier, K. Thrane, J.N. Connelly and B.S. Meyer, Science 316, 1178- (2007)

[128] V. Tatischeff, J. Duprat and N. de Séréville, Astrophys. J. 714, L26-L30 (2010)

[129] J. Villeneuve, M. Chaussidon and G. Libourel, Science 325, 985-988 (2009)

[130] J. Duprat and V. Tatischeff, Astrophys. J. 671, L69-L72 (2007)

[131] A.N. Krot, et al., Geochim. Cosmochim. Acta 73, $4963-4997$ (2009)

[132] C.M. Gray and D.A. Papanastassiou, Icarus 20, 213 (1973)

[133] J. Blichert-Toft, B. Zanda, D.S. Ebel and F. Albarède, Earth Planet. Sci. Lett. 300, 152-163 (2010)

[134] Y. Amelin, A. Kaltenbach, T. Iizuka, C.H. Stirling, T.R. Ireland, M. Petaev and S.B. Jacobsen, Earth Planet. Sci. Lett. 300, 343-350 (2010)

[135] G.A. Brennecka, S. Weyer, M. Wadhwa, P.E. Janney, J. Zipfel and A.D. Anbar, Science 327, 449-451 (2010)

[136] C. Patterson, Geochim. Cosmochim. Acta 10, 230-237 (1956)

[137] A. Bouvier and M. Wadhwa, Nature Geosci. 3, 637-641 (2010)

[138] Y. Amelin, A.N. Krot, I.D. Hutcheon and A.A. Ulyanov, Science 297, 1678-1683 (2002)

[139] A.N. Krot and K. Keil, Meteoritics Planet. Sci. 37, 91-111 (2002)

[140] S. Itoh and H. Yurimoto, Nature 423, 728-731 (2003)

[141] K. Thrane, M. Bizzarro and J.A. Baker, Astrophys. J. 646, L159-L162 (2006)

[142] J.N. Connelly, Y. Amelin, A.N. Krot and M. Bizzarro, Astrophys. J. 675, L121-L124 (2008)

[143] L. Qin, N. Dauphas, M. Wadhwa, J. Masarik and P.E. Janney, Earth Planet. Sci. Lett. 273, $94-$ 104 (2008) 
[144] J. Blichert-Toft, F. Moynier, C.-T.A. Lee, P. Telouk and F. Albarède, Earth Planet. Sci. Lett. 296, 469-480 (2010)

[145] S.G. Love, D. Joswiak and D.E. Brownlee, Lunar Planet. Sci. XXIV, 901-902 (1993)

[146] C. Engrand, E. Deloule, F. Robert, M. Maurette and G. Kurat, Meteoritics Planet. Sci. 34, 773787 (1999)

[147] C. Engrand, K.D. McKeegan and L.A. Leshin, Geochim. Cosmochim. Acta 63, 2623-2636 (1999)

[148] J.A. Burns, P.L. Lamy and S. Soter, Icarus 40, 1-48 (1979)

[149] D. Vokrouhlický and P. Farinella, Nature 407, 606-608 (2000)

[150] T. Mothé-Diniz, J.M.r. Carvano and D. Lazzaro, Icarus 162, 10-21 (2003)

[151] D.L. Buczkowski, O.S. Barnouin-Jha and L.M. Prockter, Icarus 193, 39-52 (2008)

[152] L.F. Lim and L.R. Nittler, Icarus 200, 129-146 (2009)

[153] A. Meibom and B.E. Clark, Meteoritics Planet. Sci. 34, 7-24 (1999)

[154] M. Gounelle, M.E. Zolensky, J.-C. Liou, P.A. Bland and O. Alard, Geochim. Cosmochim. Acta 67, 507-527 (2003)

[155] M. Gounelle, C. Engrand, O. Alard, P.A. Bland, M.E. Zolensky, S.S. Russell and J. Duprat, Geochim. Cosmochim. Acta 69, 3431-3443 (2005)

[156] T. Yada, et al., Geochim. Cosmochim. Acta 69, 5789-5804 (2005)

[157] M. Gounelle, C. Engrand, M. Maurette, G. Kurat, K.D. McKeegan and F. Brandstätter, Meteoritics Planet. Sci. 40, 917-932 (2005)

[158] J. Aléon, C. Engrand, L.A. Leshin and K.D. McKeegan, Geochim. Cosmochim. Acta 73, 45584575 (2009)

[159] W.F. Bottke, H.F. Levison, D. Nesvorny, A. Morbidelli and M. Gounelle (2008) The collisional evolution of objects captured in the outer asteroid belt during the late heavy bombardment. In Asteroids, Comets, Meteors, pp. \#8096, Baltimore.

[160] P. Rochette, L. Folco, C. Suavet, M. van Ginneken, J. Gattacceca, N. Perchiazzi, R. Braucher and R.P. Harvey, Proc. Nat. Acad. Sci. 105, 18206-18211 (2008)

[161] C. Suavet, A. Alexandre, I.A. Franchi, J. Gattacceca, C. Sonzogni, R.C. Greenwood, L. Folco and P. Rochette, Earth Planet. Sci. Lett. 293, 313-320 (2010)

[162] C. Cordier, L. Folco and S. Taylor, Geochim. Cosmochim. Acta 75, 1199-1215 (2011)

[163] J. Leitner, T. Stephan, A.T. Kearsley, F. Hoerz, G.J. Flynn and S.A. Sandford, Meteoritics Planet. Sci. 43, 161-185 (2008)

[164] A.T. Kearsley, et al., Meteoritics Planet. Sci. 43, 41-73 (2008)

[165] H. Leroux, et al., Meteoritics Planet. Sci. 43, 143-160 (2008)

[166] L. Grossman, Geochim. Cosmochim. Acta 36, 597-619 (1972)

[167] D.S. Ebel and L. Grossman, Geochim. Cosmochim. Acta 64, 339-366 (2000)

[168] L. Grossman, et al., Geochim. Cosmochim. Acta 72, 3001-3021 (2008)

[169] F. Albarede, Nature 461, 1227-1233 (2009)

[170] R.H. Hewins, Ann. Rev. Earth Planet. Sci. 25, 61-83 (1997)

[171] B. Zanda, Earth Planet. Sci. Lett. 224, 1-17 (2004)

[172] S. Desch, Nature 441, 416-417 (2006)

[173] J.N. Cuzzi and C.M.O.D. Alexander, Nature 441, 483-485 (2006)

[174] S.J. Desch and H.C. Connolly, Jr., Meteoritics Planet. Sci. 37, 183-207 (2002)

[175] C.M.O.D. Alexander, J.N. Grossman, D.S. Ebel and F.J. Ciesla, Science 320, 1617-1619 (2008)

[176] G. Libourel and A.N. Krot, Earth Planet. Sci. Lett. 254, 1-8 (2007)

[177] G. Libourel and M. Chaussidon, Earth Planet. Sci. Lett. 301, 9-21 (2011)

[178] M. Chaussidon, G. Libourel and A.N. Krot, Geochim. Cosmochim. Acta 72, 1924-1938 (2008)

[179] L. Tissandier, G. Libourel and F. Robert, Meteoritics Planet. Sci. 37, 1377-1389 (2002)

[180] G. Libourel, A.N. Krot and L. Tissandier, Earth Planet. Sci. Lett. 251, 232-240 (2006)

[181] J. Kissel and F.R. Krueger, Nature 328, 117 (1987) 
[182] M.N. Fomenkova, J.F. Kerridge, K. Marti and L.A. McFadden, Science 258, 266-269 (1992)

[183] M.N. Fomenkova, Space Sci. Rev. 90, 109-114 (1999)

[184] E.K. Jessberger, Space Sci. Rev. 90, 91-97 (1999)

[185] E. Dobrică, Les micrométéorites CONCORDIA : des neiges antarctiques aux glaces cométaires. $\mathrm{PhD}$ thesis. Université Paris Sud XI, Orsay (2010)

[186] D.H. Wooden, Space Sci. Rev. 138, 75-108 (2008)

[187] M.E. Zolensky, et al., Science 314, 1735-1739 (2006)

[188] K. Tomeoka, N. Tomioka and I. Ohnishi, Meteoritics Planet. Sci. 43, 273-284 (2008)

[189] M. Zolensky, et al., Meteoritics Planet. Sci. 43, 261-272 (2008)

[190] T. Nakamura, et al., Science 321, 1664-1667 (2008)

[191] G.J. Flynn, et al., Science 314, 1731-1735 (2006)

[192] L.P. Keller, et al., Science 314, 1728-1731 (2006)

[193] S.B. Simon, et al., Meteoritics Planet. Sci. 43, 1861-1877 (2008)

[194] R. van Boekel, et al., Nature 432, 479-482 (2004)

[195] B.A. Sargent, et al., Astrophys. J. 690, 1193-1207 (2009)

[196] B.A. Sargent, et al., The Astrophysical Journal Supplement Series 182, 477-508 (2009)

[197] D.M. Watson, et al., The Astrophysical Journal Supplement Series 180, 84-101 (2009)

[198] M. Roskosz, J. Gillot, F. Capet, P. Roussel and H. Leroux, Astrophys. J. 707, L174-L178 (2009)

[199] Lisse, C.M., Wyatt, M.C., Chen, C.H., Morlok, A., Watson, D.M., Manoj, P., Sheehan, P., Currie, T.M., Thebault, P., and Sitko M.L., Spitzer Evidence for a Late Heavy Bombardment and the Formation of Urelites in $\eta$ Corvi at $\sim 1$ Gyr. Astrophys. J., accepted for publication (2011)

[200] R.N. Clayton, L. Grossman and T.K. Mayeda, Science 182, 485-488. (1973)

[201] R.N. Clayton, T.K. Mayeda and N. Onuma, Earth Planet. Sci. Lett. 30, 10-18 (1976)

[202] R.N. Clayton, Ann. Rev. Earth Planet. Sci. 21, 115-149 (1993)

[203] R.N. Clayton and T.K. Mayeda, Geochim. Cosmochim. Acta 63, 2089-2104 (1999)

[204] K.D. McKeegan, et al., Science 332, 1528-1532 (2011)

[205] K. Hashizume and M. Chaussidon, Nature 434, 619-622 (2005)

[206] T.R. Ireland, P. Holden, M.D. Norman and J. Clarke, Nature 440, 776-778 (2006)

[207] K. Hashizume and M. Chaussidon, Geochim. Cosmochim. Acta 73, 3038-3054 (2009)

[208] A. Bischoff, et al., Geochim. Cosmochim. Acta 57, 1587-1603 (1993)

[209] A. Bischoff, et al., Meteoritics 29, 264-274 (1994)

[210] R.N. Clayton and T.K. Mayeda, Earth Planet. Sci. Lett. 40, 168-174 (1978)

[211] R.N. Clayton and T.K. Mayeda, Earth Planet. Sci. Lett. 62, 1-6 (1983)

[212] R.N. Clayton and T.K. Mayeda, Earth Planet. Sci. Lett. 67, 151-161 (1984)

[213] R.N. Clayton, N. Onuma, L. Grossman and T.K. Mayeda, Earth Planet. Sci. Lett. 34, 209-224 (1977)

[214] R.N. Clayton, T.K. Mayeda and A.E. Rubin, J. Geophys. Res. 89, 245 (1984)

[215] R.N. Clayton, T.K. Mayeda, J.N. Goswami and E.J. Olsen, Geochim. Cosmochim. Acta 55, 2317-2337 (1991)

[216] R.N. Clayton and T.K. Mayeda, Geochim. Cosmochim. Acta 60, 1999-2017 (1996)

[217] R.N. Clayton and T.K. Mayeda, Lunar Planet. Sci. XXXII, \#1885 (CD-ROM) (2001)

[218] P.G. Brown, et al., Science 290, 320-325 (2000)

[219] L.P. Keller, K.L. Thomas, R.N. Clayton, T.K. Mayeda, J.M. DeHart and D.S. McKay, Geochim. Cosmochim. Acta 58, 5589-5598 (1994)

[220] T.K. Mayeda, R.N. Clayton and K. Yanai, PNIPR 46, 144-150 (1987)

[221] T.K. Mayeda, J. Shearer and R.N. Clayton (1975) Oxygen isotope fractionation in Apollo 17 rocks. In Lunar and Planetary Science Conference Proceedings, pp. 1799-1802.

[222] T.K. Mayeda, R.N. Clayton and C.A. Molini-Velsko, Geophys. Res. Lett. 10, 799 (1983)

[223] M.W. Rowe, R.N. Clayton and T.K. Mayeda, Geochim. Cosmochim. Acta 58, 5341-5347 (1994) 
[224] M.K. Weisberg, M. Prinz, H. Kojima, K. Yanai, R.N. Clayton and T.K. Mayeda, Geochim. Cosmochim. Acta 55, 2657-2669 (1991)

[225] M.K. Weisberg, M. Prinz, R.N. Clayton and T.K. Mayeda, Geochim. Cosmochim. Acta 57, 1567-1586 (1993)

[226] R.N. Clayton, Nature 415, 860-861 (2002)

[227] J.R. Lyons and E.D. Young, Nature 435, 317-320 (2005)

[228] J.R. Lyons, E.A. Bergin, F.J. Ciesla, A.M. Davis, S.J. Desch, K. Hashizume and J.E. Lee, Geochim. Cosmochim. Acta 73, 4998-5017 (2009)

[229] H. Yurimoto and K. Kuramoto, Science 305, 1763-1766 (2004)

[230] S. Chakraborty, M. Ahmed, T.L. Jackson and M.H. Thiemens, Science 321, 1328-1331 (2008)

[231] S. Chakraborty, M. Ahmed, T.L. Jackson and M.H. Thiemens, Science 324, 1516 (2009)

[232] J.R. Lyons, R.S. Lewis and R.N. Clayton, Science 324, 1516 (2009)

[233] S.R. Federman and E.D. Young, Science 324, 1516 (2009)

[234] Q.-Z. Yin, X. Shi, C. Chang and C.-Y. Ng, Science 324, 1516 (2009)

[235] M.H. Thiemens, Science 283, 341-345 (1999)

[236] Y.Q. Gao and R.A. Marcus, Science 293, 259-263 (2001)

[237] F. Robert and C. Camy-Peyret, Ann.Geophys. 19, 229-244 (2001)

[238] R.A. Marcus, J. Chem. Phys. 121, 8201-8211 (2004)

[239] G. Dominguez, Astrophys. J. 713, L59-L63 (2010)

[240] K.D. McKeegan, et al., Science 314, 1724-1728 (2006)

[241] E. Jehin, J. Manfroid, D. Hutsemékers, C. Arpigny and J.-M. Zucconi, Earth Moon and Planets 105, 167-180 (2009)

[242] J.I. Simon, I.D. Hutcheon, S.B. Simon, J.E.P. Matzel, E.C. Ramon, P.K. Weber, L. Grossman and D.J. DePaolo, Science 331, 1175-1178 (2011)

[243] S.A. Sandford, et al., Science 314, 1720-1724 (2006)

[244] D.P. Glavin, J.P. Dworkin and S.A. Sandford, Meteoritics Planet. Sci. 43, 399-413 (2008)

[245] G. Matrajt, et al., Meteoritics Planet. Sci. 43, 315-334 (2008)

[246] G.M. Muñoz Caro, E. Dartois and K. Nakamura-Messenger, Astron. Astrophys. 485, 743-751 (2008)

[247] J.E. Elsila, D.P. Glavin and J.P. Dworkin, Meteoritics Planet. Sci. 44, 1323-1330 (2009)

[248] S.J. Clemett, S.A. Sandford, K. Nakamura-Messenger, F. Hörz and D.S. McKay, Meteoritics Planet. Sci. 45, 701-722 (2010)

[249] B.T. De Gregorio, R.M. Stroud, L.R. Nittler, C.M.O.D. Alexander, A.L.D. Kilcoyne and T.J. Zega, Geochim. Cosmochim. Acta 74, 4454-4470 (2010)

[250] H. Balsiger, K. Altwegg and J. Geiss, J. Geophys. Res. 100, 5827-5834 (1995)

[251] P. Eberhardt, M. Reber, D. Krankowsky and R.R. Hodges, Astron. Astrophys. 302, 301-316 (1995)

[252] D. Bockelée-Morvan, et al., Icarus 133, 147-162 (1998)

[253] R. Meier, T.C. Owen, H.E. Matthews, D.C. Jewitts, D. Bockelée-Morvan, N. Biver, J. Crovisier and D. Gautier, Science 279, 842-844 (1998)

[254] H.A. Weaver, M.F. A'Hearn, C. Arpigny, M.R. Combi, P.D. Feldman, G.-P. Tozzi, N. Dello Russo, L.M. Feaga and M.C. Festou (2008) Atomic deuterium emission and the D/H ration in comets. In Asteroids, Comets, Meteors, pp. \#8216, Baltimore.

[255] D. Hutsemékers, J. Manfroid, E. Jehin, J.-M. Zucconi and C. Arpigny, Astron. Astrophys. 490, L31-L34 (2008)

[256] G.L. Villanueva, M.J. Mumma, B.P. Bonev, M.A. Di Santi, E.L. Gibb, H. Böhnhardt and M. Lippi, Astrophys. J. 690, L5-L9 (2009)

[257] C. Lecluse and F. Robert, Geochim. Cosmochim. Acta 58, 2927-2939 (1994)

[258] R. Meier, T.C. Owen, D.C. Jewitt, H.E. Matthews, M. Senay, N. Biver, D. Bockelée-Morvan, J. Crovisier and D. Gautier, Science 279, 1707-1710 (1998) 
[259] T.J. Millar, A. Bennett and E. Herbst, Astrophys. J. 340, 906-920 (1989)

[260] L. Remusat, F. Palhol, F. Robert, S. Derenne and C. France-Lanord, Earth Planet. Sci. Lett. 243, 15-25 (2006)

[261] J. Aléon, C. Engrand, F. Robert and M. Chaussidon, Geochim. Cosmochim. Acta 65, 4399-4412 (2001)

[262] L. Remusat and et al., Astrophys. J. 713, 1048-1058 (2010)

[263] H. Busemann, A.F. Young, C.M.O.D. Alexander, P. Hoppe, S. Mukhopadhyay and L.R. Nittler, Science 312, 727-730 (2006)

[264] A. Meibom, A.N. Krot, F. Robert, S. Mostefaoui, S.S. Russell, M.I. Petaev and M. Gounelle, Astrophys. J. 656, L33-L36 (2007)

[265] B. Marty, L. Zimmermann, P.G. Burnard, R. Wieler, V.S. Heber, D.L. Burnett, R.C. Wiens and P. Bochsler, Geochim. Cosmochim. Acta 74, 340-355 (2010)

[266] B. Marty, M. Chaussidon, R.C. Wiens, A.J.G. Jurewicz and D.S. Burnett, Science 332, 1533 1536 (2011)

[267] K. Hashizume, M. Chaussidon, B. Marty and F. Robert, Science 290, 1142-1145 (2000)

[268] D. Bockelée-Morvan, et al., Astrophys. J. 679, L49-L52 (2008)

[269] R. Schulz, E. Jehin, J. Manfroid, D. Hutsemékers, C. Arpigny, A. Cochran, J.-M. Zucconi and J.A. Stüwe, Planet. Space Sci. 56, 1713-1718 (2008)

[270] J. Manfroid, E. Jehin, D. Hutsemékers, A. Cochran, J.-M. Zucconi, C. Arpigny, R. Schulz, J.A. Stüwe and I. Ilyin, Astron. Astrophys. 503, 613-624 (2009)

[271] J. Aléon, Astrophys. J. 722, 1342-1351 (2010)

[272] D.H. Wooden, H.M. Butner, D.E. Harker and C.E. Woodward, Icarus 143, 126-137 (2000)

[273] R.C. Ogliore, A.J. Westphal, Z. Gainsforth, A.L. Butterworth, S.C. Fakra and M.A. Marcus, Meteoritics Planet. Sci. 44, 1675-1681 (2009)

[274] A.J. Westphal, S.C. Fakra, Z. Gainsforth, M.A. Marcus, R.C. Ogliore and A.L. Butterworth, Astrophys. J. 694, 18-28 (2009)

[275] D. Bockelée-Morvan, D. Gautier, F. Hersant, J.M. Huré and F. Robert, Astron. Astrophys. 384, 1107-1118 (2002)

[276] F.J. Ciesla, Science 318, 613- (2007)

[277] F.H. Shu, H. Shang, A.E. Glassgold and T. Lee, Science 277, 1475-1479 (1997)

[278] D. Vinković, Nature 459, 227-229 (2009)

[279] I. Bertini, Planet. Space Sci. 59, 365-377 (2011) 